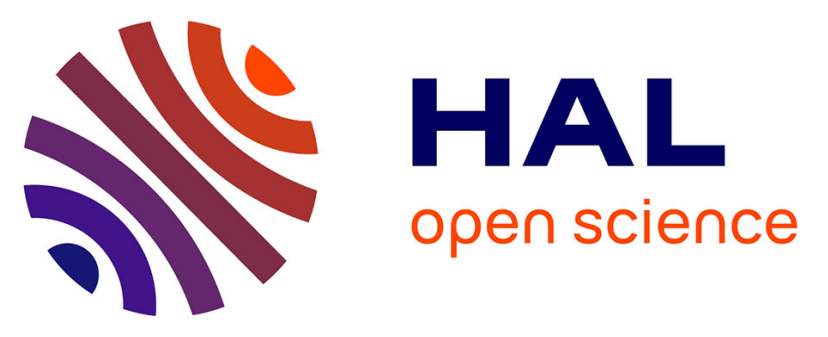

\title{
Performance comparison of six solar-powered air-conditioners operated in five places
}

\author{
Michel Pons, Guillaume Anies, François Boudehenn, Paul Bourdoukan, Jean \\ Castaing-Lasvignottes, Gianpiero Evola, Amandine Le Denn, Nolwenn Le \\ Pierrès, Olivier Marc Marc, Nathalie Mazet, et al.
}

\section{To cite this version:}

Michel Pons, Guillaume Anies, François Boudehenn, Paul Bourdoukan, Jean Castaing-Lasvignottes, et al.. Performance comparison of six solar-powered air-conditioners operated in five places. Energy, 2012, 46, pp.471-483. 10.1016/j.energy.2012.08.002 . hal-01836603

\section{HAL Id: hal-01836603 https://hal.science/hal-01836603}

Submitted on $30 \mathrm{Jul} 2018$

HAL is a multi-disciplinary open access archive for the deposit and dissemination of scientific research documents, whether they are published or not. The documents may come from teaching and research institutions in France or abroad, or from public or private research centers.
L'archive ouverte pluridisciplinaire HAL, est destinée au dépôt et à la diffusion de documents scientifiques de niveau recherche, publiés ou non, émanant des établissements d'enseignement et de recherche français ou étrangers, des laboratoires publics ou privés. 


\title{
Performance comparison of six solar-powered air-conditioners operated in five places
}

\author{
M. Pons ${ }^{1 *}$, G. Anies ${ }^{2}$, F. Boudehenn ${ }^{3}$, P. Bourdoukan ${ }^{4,5}$, J. Castaing-Lasvignottes ${ }^{2,8}$, \\ G. Evola ${ }^{6,10}$, A. Le Denn ${ }^{7}$, N. Le Pierrès ${ }^{6}$, O. Marc ${ }^{8}$, N. Mazet ${ }^{9}$, D. Stitou ${ }^{9}$, and F. Lucas ${ }^{8}$.
}

${ }^{1}$ CNRS-LIMSI UPR 3251, BP 133, Bât 508 Campus, 91403 Orsay Cedex, France

${ }^{2}$ LaTEP-UPPA, Rue Jules Ferry, BP7511, 64075 Pau Cedex, France

${ }^{3}$ CEA/LITEN, INES, Savoie Technolac, 73376 Le Bourget du Lac Cedex, France

${ }^{4}$ LEPTIAB, Univ. La Rochelle, Avenue Michel Crépeau, 17042 La Rochelle Cedex 1, France

${ }^{5}$ SORANE SA, Route du Bois 37, 1024 Ecublens, Switzerland

${ }^{6}$ LOCIE, Univ. Savoie, Savoie Technolac, 73376 Le Bourget du Lac Cedex, France

${ }^{7}$ TECSOL, Tecnosud, 105 Avenue Alfred Kastler, 66004 Perpignan Cedex, France

${ }^{8}$ PIMENT, Univ. La Réunion, BP 373, 97455 St Pierre Cedex, France

${ }^{9}$ CNRS-PROMES UPR8251, Tecnosud, Rambla de la Thermodynamique, 66100 Perpignan, France

${ }^{10}$ Present address : CNRS-LEPMI, Savoie Technolac, BP 332, 73376 Le Bourget du Lac Cedex, France

* Corresponding author. Tel. +33 169858 075. E-mail address: Michel.pons@limsi.fr

\begin{abstract}
Six solar-powered air-conditioners, based on four principles $\left(\mathrm{LiBr}+\mathrm{H}_{2} \mathrm{O}\right.$ liquid sorption, silicagel + water solid sorption, $\mathrm{BaCl}_{2}+\mathrm{NH}_{3}$ thermochemical reaction, and desiccant + humid air open cycles) have been operated in five places (from the low-altitude Alps to a tropical island including Mediterranean Sea shore). A common experimentation procedure was applied over months, except for some cases, and during several years. Data were recorded, gathered, and analyzed similarly for the six units. Is established a sound framework based on relevant quantities, some non-dimensional and others dimensional but referred to relevant scales, with the purpose that direct comparison of results is sensible. Similarly, are defined the sub-units to be considered for further analysis. This framework is applied to (i) data averaged over long periods, and (ii) data obtained on one single day with given insolation. Comprehension obtained from comparison in that framework gives access to notions as different as (i) fundamental differences between systems, (ii) aging of components, and (iii) non-linearity of the basic operation of such solar-powered units. The theoretical analysis of this nonlinearity is developed. The framework established in this article could thus be used for comparing other solar-powered processes.
\end{abstract}

Pons M., Anies G., Boudehenn F., Bourdoukan P., Castaing-Lasvignottes J., Evola G., Le Denn A., Le Pierrès N., Marc O., Mazet N., Stitou D., and Lucas F., Performance comparison of six solarpowered air-conditioners operated in five places, Energy, 46, pp.471-483 (DOI: 10.1016/j.energy.2012.08.002), 2012. 


\section{Highlights}

- Comparative study of six units, in five places, with four sorption techniques.

- Experimental seasonal solar COP for air-conditioning ranges from 0.08 to 0.20.

- Liquid sorption seems to be more efficient than other principles.

- Effective electricity consumption is severely affected by initial design choices.

- Aging of solar collectors may also be a real issue.

\section{Keywords}

Experimentation; absorption; adsorption; desiccant; thermochemical; solar refrigeration.

\section{Nomenclature}

Notations follow the usual conventions given in [1] except for these ones

$A_{S C}$ total area of the solar collectors $\left[\mathrm{m}^{2}\right]$

Subscripts

$c_{W}$ specific consumption of water

$1 d$ one-day

$\left[1 . \mathrm{kWh}_{\text {cold }}{ }^{-1}\right]$

ac air-conditioning

$N_{d} \quad$ total number of days of the operation

d dissipation

period

el electrical

Greek symbols

$h$ heating

$\eta \quad$ collector efficiency

sf solar field

Superscripts

* objective (demand)

sol solar

w water

Pons M., Anies G., Boudehenn F., Bourdoukan P., Castaing-Lasvignottes J., Evola G., Le Denn A., Le Pierrès N., Marc O., Mazet N., Stitou D., and Lucas F., Performance comparison of six solarpowered air-conditioners operated in five places, Energy, 46, pp.471-483 (DOI: 10.1016/j.energy.2012.08.002), 2012. 


\section{Introduction}

Development of air-conditioning offers more and more comfort and safety to mankind. However, the most widespread technology of commercial air-conditioners, electricitypowered compression cycles, must face a paradox: the more air-conditioners installed in a city, the more heat is released to urban atmosphere, and the more ambient air temperature increases. This phenomenon, called urban heat islands [2], makes air temperature of large cities increase by as much as $10 \mathrm{~K}$ compared to countryside [3], with two negative consequences. First, cooling load of buildings is almost doubled; second, performance efficiency of air-conditioners is reduced by about one fourth. Both effects unfortunately add to each other, so that the peak electricity demand for cooling purposes may be tripled [3]. This vicious circle is a major concern, especially with respect to energy consumption and $\mathrm{CO}_{2}$ emissions. Part of the solution probably lies in heat-powered chillers, if powered by wasteheat or solar energy. Indeed, an air-conditioner that uses energy that would anyhow be released to urban atmosphere, does not import any external energy into the global energy balance of cities. Current heat-powered chillers are based on various principles $[4,5]$ :

- liquid sorption (typically $\mathrm{LiBr}+\mathrm{H}_{2} \mathrm{O}$ ), solid sorption (adsorption or thermochemical reaction), or ejection: technology based on liquid sorption or on silica-gel is at commercial stage of development, the other ones are still experimental;

- closed or open thermodynamic cycle: in the former, the unit exchanges only heat with its surroundings, in the latter mass is also exchanged, most often humid air;

- continuous or discontinuous cycle: possibility of steady-state, or alternation of heating and cooling periods.

There are good reasons for using solar radiation as power-energy of such air-conditioners [6]. First, globally speaking, cooling demand and insolation are positively correlated in time and intensity. Second, current commercial heat-powered air-conditioners need heat input at $80-90^{\circ} \mathrm{C}$. This temperature level is rather well adapted to the common performance of flatplate -or evacuated tube- solar collectors, the cost of which is rather low compared to concentrators. Lastly, installing solar collectors on the roof of a building forcedly reduces its solar radiative gain and therefore tends by itself to slightly decrease the cooling demand of the building. As a matter of fact, many solar-powered air-conditioners solar air-conditioning have been tested around the world during the last years [7-16]. In addition, the components of those installations have reached commercial stage of development, at least for some technologies. Actually and when looking closely, one should not use the name air-conditioners for such units. Indeed, solar energy is essentially unstable, a feature which prevents solar-powered chillers to assign steady comfort conditions $\left(e . g .25^{\circ} \mathrm{C}\right)$ to indoor air. One should rather call them chillers for refreshing indoor air. We nevertheless use the words air-conditioning for the sake of convenience.

The above-cited articles show that feasibility of solar-powered air-conditioning no longer needs to be proven. The current issue consists of comparing performance of the various technologies under test here and there. Such a comparison can be sound only if the framework is robust and accounts for the many characteristics of solar energy. Indeed, performance of solar-powered systems depends on both the technology and the climate, especially insolation

Pons M., Anies G., Boudehenn F., Bourdoukan P., Castaing-Lasvignottes J., Evola G., Le Denn A., Le Pierrès N., Marc O., Mazet N., Stitou D., and Lucas F., Performance comparison of six solarpowered air-conditioners operated in five places, Energy, 46, pp.471-483 (DOI: 10.1016/j.energy.2012.08.002), 2012. 
and outdoor temperature. More exactly, performance depends on how well the technology and design are adapted to the local climate and to the cooling demand. Non-material features, such as the monitoring procedure, might also be of importance. In addition, several criteria are usually involved in the notion of performance: for instance energetic performance is evaluated by at least two figures of merit, one for cold production, and one for electricity consumption; other practical features hardly mentioned in the literature such as water consumption, areas, volumes, or masses, could also be considered. Lastly, the answer to such a complex problem is neither unique nor universal.

This article results from a long-term study cooperatively conducted by the authors with that problematic in mind. In order to make comparison sensible, the authors (i) adopted a common comparison framework, which included the experimental procedure, (ii) applied this procedure for long enough periods (at least one air-conditioning season, several when possible), (iii) interpreted their experimental data in the same terms, and (iv) gathered their results for comparison. This study, called the ORASOL project $[17,18]$, was conducted over four years. This article altogether presents the comparison framework (next section) and the six units tested this way (section 3) before discussing the results of comparison (section 4) and developing a comprehensive theory for non-linear effects (section 5).

\section{The comparison framework}

To the authors' best knowledge, the literature on long-term evaluation of performance and on performance comparison between solar-powered air-conditioners is scarce. The latter topics is most often approached numerically [19-21]. Unfortunately, a numerical model, even completed with exergy analysis like in [22], cannot reproduce the actual behavior of a unit operated (i) in real insolation and outdoor temperature, (ii) in off-design conditions, and (iii) with non-optimal control procedures. One must then rely on experimental data. The University Carlos III Madrid published such data on an experiment with a $\mathrm{LiBr}+\mathrm{H}_{2} \mathrm{O}$ unit [10, 11]. In the present article are compared the performances effectively measured on six solar air-conditioners over whole seasons. Four working principles were tested: liquid sorption, solid sorption with short cycles, thermochemical reaction with daily cycles, and desiccant open cycles. The six units are operated in five places in France : Perpignan, Le Bourget du Lac, Pau, La Rochelle, and Saint-Pierre-de-La-Réunion, see Fig. 1. As the framework elaborated prior to the tests included guidelines for operation, performance comparison was reasonably possible. To our knowledge such a comparative work has never been done before; and we think that the comparison framework elaborated herein can be used by others in future comparative studies.

\subsection{Experimental procedure}

The six units are respectively named Solaclim (in Perpignan), Solera (in Le Bourget du Lac), Rafsol (in Saint-Pierre-de-La-Réunion), Aquisol (in Pau,) Desic (in La Rochelle) and Climsol (in Perpignan). Their main technical characteristics are given in Table 1 and the units are described in more details in Section 3. They were almost designed for the same purpose: to refresh premises of professional use, e.g. classrooms or offices. The absence of cooling demand after 6-7 pm or during the week-ends makes this application especially well-adapted to solar energy. Four of the six units were effectively used for refreshing indoor air. The two other ones (Desic and Aquisol) were operated with artificial cooling loads: a prescribed sensible load was mimicked via electrical heaters. The notion of refreshment means that the machines were not designed for insuring standard comfort conditions (e.g temperature below

Pons M., Anies G., Boudehenn F., Bourdoukan P., Castaing-Lasvignottes J., Evola G., Le Denn A., Le Pierrès N., Marc O., Mazet N., Stitou D., and Lucas F., Performance comparison of six solarpowered air-conditioners operated in five places, Energy, 46, pp.471-483 (DOI: 10.1016/j.energy.2012.08.002), 2012. 
$26^{\circ} \mathrm{C}$, like with air-conditioning) in any case, but rather for maintaining indoor temperature at $5-8{ }^{\circ} \mathrm{C}$ below outdoor air. We can however report that standard comfort temperature was experimentally achieved most of the time for three of the six units.

The experimental procedure required that no additional heat were added to the solar input during the tests: the solar fraction (proportion of primary energy supplied by the solar collectors) is therefore $100 \%$ for all units. The units were also to be run over whole airconditioning seasons. They were effectively operated from two to four months depending on the location, except for Desic and Aquisol that could only be tested on short periods. Every day of the operation period is considered in the forthcoming analysis, whatever the climatic conditions -overcast or clear sky- whatever the cooling load -partial or total- and also including days when the unit was stopped for maintenance or malfunction. Only the days when the unit was stopped for purely experimental reasons (for instance changing a thermocouple implemented for experiments only and useless otherwise), were withdrawn from the statistics. All the energies presented in the following are thus obtained by integrating the corresponding fluxes over every day of the so-defined period.

One unit (Rafsol) could be operated with that procedure for three years one after the other, and three units (Climsol, Solaclim and Solera) for two years. The experimental conditions recorded for each unit are given in Table 2, where each operation year is presented separately when relevant. The number of operation days mainly depends on the climatic conditions, but it can be mentioned that some units were operated more than required, for the sake of experimentation. For each year, the reported insolation is the average over the whole operation period. As expected, the scatter between places is strong. Note however that the changes from one year to the next in the same place can be almost as significant. The ratio of effective operation (last line of Table 2) gives the percentage of days where the unit was actually operated, even if at partial load. This ratio shows how often maintenance and malfunctions made the unit unavailable. This data would not make sense for the units that are essentially experimental (Climsol) or when the operation period was too short (Aquisol and Desic). As the group from University Carlos III Madrid Independently applied a comparable procedure, their results are included into our comparison under the name UC3M (last column of Table 2).

\subsection{Performance data gathered for comparison}

\subsubsection{Choice of relevant figures of merit}

The units to be compared herein differ by factors as large as 5.4 with respect to collector area, 6.6 with respect to nominal cooling power of the chiller, and 1.3 (if not 1.6) with respect to average daily insolation. It is thus important, but not straightforward, to define figures of merit that (i) represent the different aspects of the efficiency of the units, (ii) can be compared between tested units in a direct and correct manner, i.e. regardless of the effects due to climate or size, and without unjustly favoring or penalizing any of the tested technologies, and (iii) can be directly interpreted in terms of design or operation by an end-user who would plan to install such a solar-powered air-conditioner.

For instance, cold production can be given in various terms:

Pons M., Anies G., Boudehenn F., Bourdoukan P., Castaing-Lasvignottes J., Evola G., Le Denn A., Le Pierrès N., Marc O., Mazet N., Stitou D., and Lucas F., Performance comparison of six solarpowered air-conditioners operated in five places, Energy, 46, pp.471-483 (DOI: 10.1016/j.energy.2012.08.002), 2012. 
- nominal cooling rate $\left[\dot{Q}_{a c}\right.$, in $\mathrm{kW}$, i.e. the heat flux transmitted to the chiller (or the cold storage) by the cold distribution loop in nominal conditions (e.g. with an incident solar flux of 1000 W.m ${ }^{-2}$ );

- cold production during one whole day $\left[Q_{a c}\right.$, in $\left.\mathrm{kWh}\right]$;

- daily cold production averaged over a given period $\left[\overline{Q_{a c}}\right.$, in $\mathrm{kWh}$ per day, abbreviated as $\mathrm{kWh}_{\mathrm{d}}$ in the following];

- daily cold production per unit area of solar collectors $\left[q_{a c}=Q_{a c} / A_{s c}\right.$, in $\left.\mathrm{kWh}_{\mathrm{d}} \cdot \mathrm{m}^{-2}\right]$;

- solar COP, which is the ratio of cold production and insolation. Like for cold production itself, one may consider nominal solar COP (ratio of heat fluxes in nominal conditions), daily solar COP (for one given day), or average solar COP (averaged over a given period).

Among all those quantities, the average solar COP is the least dependent on climate and unit size; it is thus the most useful quantity from the end-user's viewpoint. Indeed, if an enduser knows (i) the daily amount of cold he needs to produce in average, $Q_{a c}^{*}$ [in kWh per day], (ii) the average daily insolation during the air-conditioning season at the place where the unit will be installed, $\overline{q_{\text {sol }}}$ [in $\left.\mathrm{kWh}_{\mathrm{d}} \cdot \mathrm{m}^{-2}\right]$, and (iii) the average solar COP $\overline{C O P_{\text {sol }}}$ he can expect from a given technology, then he can easily evaluate the area of solar collectors to be installed, according to $A_{s c}^{*}=Q_{a c}^{*} /\left(\overline{C O P_{s o l}} \cdot \overline{q_{s o l}}\right)$. The average solar COP is thus the first figure of merit considered herein.

If the relation between insolation and cold production is important, electricity consumption cannot be neglected. If sorption chillers are essentially heat-powered, some of their components and auxiliary devices consume electricity. As solar air-conditioners are usually designed for replacing compression air-conditioners and thus avoiding their electricity consumption, it is important to quantify the actual electricity consumption of the solar units and to finally compare it to what would have been consumed by a compression system. This is why the whole electricity consumption of the tested units was monitored all along the operation period, including the pumps for circulating the heat transfer fluids in the various loops (solar field, cooling tower, etc.), as well as the fans (cooling tower), the chiller itself (solution pump), the electronics, and all the components necessary for normal operation, security and maintenance. The components related to the cold distribution loop (fan-coils) and those installed for purely experimental purposes (mostly sensors and electronic devices) were excluded from that monitoring. The most useful figure for the end-user to evaluate the electricity consumption given an expected cold production $Q_{a c}^{*}$, is the ratio of the two quantities. We did not use the notion of electrical COP (cold production divided by electrical consumption) because it raises a thermodynamic paradox in the present case. Indeed, any COP, including the electrical COP, is bounded by the Carnot COP, i.e. the COP of the reversible cycle operated between the same energy sources. However, there exist solarpowered refrigerators that do not consume electricity at all [23-25]. Such refrigerators would then have an infinite electrical COP, which is in full contradiction with the Second Law. The paradox disappears when considering the inverse quantity, i.e. electricity divided by cold; this is our second figure of merit. To the authors' knowledge, electricity consumption of solar-

Pons M., Anies G., Boudehenn F., Bourdoukan P., Castaing-Lasvignottes J., Evola G., Le Denn A., Le Pierrès N., Marc O., Mazet N., Stitou D., and Lucas F., Performance comparison of six solarpowered air-conditioners operated in five places, Energy, 46, pp.471-483 (DOI: 10.1016/j.energy.2012.08.002), 2012. 
powered chillers has never been reported before in the literature although our study shows that it is non-negligible. We therefore think that this data is mostly important.

Water consumption also is rarely associated to solar air-conditioners; it is never mentioned in the literature although it may be mandatory depending on the technology. By principle, the process and return air flows of desiccant cooling systems are cooled by humidification, i.e. evaporation of liquid droplets into non-saturated air. Desiccant cooling systems, for instance the Desic unit of this study, forcedly consume liquid water. Water may also be consumed in another component, the cooling tower where heat is rejected to ambient air. Indeed, with the technology of wet cooling-towers liquid water is evaporated into ambient air in order to intensify the heat flux density on the heat exchanger and thus lower both condenser and absorber temperatures. Like for the electricity consumption, water consumption if referred to the unit of cold production; this is our third figure of merit [in liter per kWh cold].

Those three figures describe the global performance of each unit and direct comparison between them makes sense. However, in order to better interpret the differences between the results, one has to analyze the different parts of the units. Good comprehension is obtained when considering only two parts for each unit: (i) the solar field, which consists of all the components which are up-hill the chiller (solar collectors, solar loop, hot storage ...), (ii) the chiller, a term which also encompasses all the components down-hill the chiller itself (cooling tower, cold storage ...) but not the loop for distributing cold. Analyzing these two systems separately gives a better insight on the global performance. For instance, the average solar COP is the product of the average efficiency of the solar field and of the COP of the chiller.

\subsubsection{Global figures of merit}

The data measured on the units are (i) the global (direct plus diffuse) insolation incident on a plane parallel to the collectors, $\dot{q}_{s o l}(t)\left[\right.$ in $\left.\mathrm{kW} . \mathrm{m}^{-2}\right]$, (ii) the heat flux effectively extracted by the chiller from the cold distribution loop, $\dot{Q}_{a c}(t)$ [in kW]. For each day $\dot{q}_{s o l}(t)$ is integrated from sunrise to sunset and $\dot{Q}_{a c}(t)$ over the total operation period of the cold distribution loop. These two integrals are respectively (i) the daily insolation $q_{s o l}(n)$ [in $\left.\mathrm{kWh}_{\mathrm{d}} \cdot \mathrm{m}^{-2}\right]$, and (ii) the daily cold production, namely: $Q_{a c}(n)=\int_{\text {day\#n }} \dot{Q}_{a c}(t) \cdot \mathrm{d} t \quad\left[\mathrm{in} \mathrm{kWh}_{\mathrm{d}}\right]$, on the considered day \#n. Then these two daily quantities are averaged over the $N_{d}$ days of the test period (as described in the experimental procedure, section 2.1); one obtains this way, (i) the average daily insolation $\overline{q_{s o l}}\left[\right.$ in $\left.\mathrm{kWh}_{\mathrm{d}} \cdot \mathrm{m}^{-2}\right]$, and (ii) the average daily cold production $\overline{Q_{a c}}=\left(\sum_{n} Q_{a c}(n)\right) / N_{d}\left[\right.$ in $\left.\mathrm{kWh}_{\mathrm{d}}\right]$.

At this point, relating $\overline{q_{s o l}}$ and $\overline{Q_{a c}}$ requires an area of solar collectors to be defined. Among all the possibilities, the total aperture area of the solar collectors, denoted $A_{s c}$, i.e. the area where insolation can actually be converted into useful heat, is the notion the most faithfully transposed from one technology to another. From now on, the size of the unit is quantified by $A_{s c}$. This reference leads to the specific average daily cold production (i.e. per unit area collector, a precision omitted in the following): $\overline{q_{a c}}=\overline{Q_{a c}} / A_{s c}\left[\mathrm{in} \mathrm{kWh}_{\mathrm{d}} \cdot \mathrm{m}^{-2}\right]$.

Pons M., Anies G., Boudehenn F., Bourdoukan P., Castaing-Lasvignottes J., Evola G., Le Denn A., Le Pierrès N., Marc O., Mazet N., Stitou D., and Lucas F., Performance comparison of six solarpowered air-conditioners operated in five places, Energy, 46, pp.471-483 (DOI: 10.1016/j.energy.2012.08.002), 2012. 
The concept of solar COP (ratio of produced cold and incident insolation) can be applied (i) at a given moment: $C O P_{s o l}(t)=\dot{q}_{a c}(t) / \dot{q}_{s o l}(t)$, where $\dot{q}_{a c}(t)=\dot{Q}_{a c}(t) / A_{s c}$; (ii) at the day $\# n: \quad C O P_{s o l}(n)=q_{a c}(n) / q_{s o l}(n)$, where $q_{a c}(n)=Q_{a c}(n) / A_{s c} ;$ or (iii) averagely on the operation period:

$$
\overline{\mathrm{COP} \text { sol }}=\overline{q_{a c}} / \overline{q_{\text {sol }}}
$$

The instantaneous $\mathrm{COP}, \mathrm{COP}_{\text {sol }}(t)$, is usually evaluated from fluxes measured during apparently steady operation under rather strong insolation (typically $900-1000 \mathrm{~W} \cdot \mathrm{m}^{-2}$ around midday). The daily COP, $\mathrm{COP}_{\text {sol }}(n)$, includes the effects of the everyday start-up and shutdown procedures which are constitutive of solar energy. As the heat dissipated in these procedures is not available to the end user, this daily COP is more reliable than the former one. It is usually evaluated for clear days, with insolation of the order of $6.5-7 \mathrm{kWh} \cdot \mathrm{m}^{-2}$. This implicit choice limits the effects of partial load on performance. The average solar COP, $\overline{C O P_{\text {sol }}}$, includes all the effects of climatic variations, partial load periods due to temporary sky coverage, overcast days, stops for maintenance, all phenomena which are constitutive of solar energy and usually tend to decrease performance. The average solar COP as defined by equation (1) is thus the most reliable figure for indicating how efficiently the whole unit converts solar radiation into cold; it is also the most useful for end-users (see section 2.2.1). However, theoretical analysis of the difference between the daily and average COPs is also developed in the following.

For the electric consumption, the experimental values recorded at time $t, \dot{W}_{e l}(t)$, are treated like cold production and insolation: (i) integration over the whole day, (ii) averaging of the daily values, and (iii) reference to the unit area of collector. As explained above, the quantity of interest is the specific average electricity consumption [in electric $\mathrm{kWh}$ per $\mathrm{kWh}$ cold] which is given by:

$$
\overline{\varpi_{e l}}=\frac{1}{N_{d} \cdot A_{s c} \cdot \overline{q_{a c}}} \sum_{n}\left[\int_{d a y \# n} \dot{W}_{e l}(t) \cdot \mathrm{d} t\right]
$$

The same procedure is applied for the consumption of water: if $\dot{V}_{w}(t)$ is the recorded value of water consumed in the whole unit (in $1 . \mathrm{s}^{-1}$ ), then the average specific consumption of water [in liters per $\mathrm{kWh}$ cold] is given by:

$$
\overline{c_{w}}=\frac{1}{N_{d} \cdot A_{s c} \cdot \overline{q_{a c}}} \sum_{n}\left[\int_{\text {day\#n }} \dot{V}_{w}(t) \cdot \mathrm{d} t\right]
$$

Those three figures of merit, $\overline{C O P_{s o l}}, \overline{\varpi_{e l}}$, and $\overline{c_{w}}$, describe the global performance of the whole unit. Following this analysis made it possible to compare performance of the six units, plus a seventh one, despite their differences.

\subsubsection{Figures of merit for the sub-systems}

Better insight on performance is gained when the respective efficiencies of the two main sub-systems are known. The two sub-systems are the solar field and the chiller. Herein the

Pons M., Anies G., Boudehenn F., Bourdoukan P., Castaing-Lasvignottes J., Evola G., Le Denn A., Le Pierrès N., Marc O., Mazet N., Stitou D., and Lucas F., Performance comparison of six solarpowered air-conditioners operated in five places, Energy, 46, pp.471-483 (DOI: 10.1016/j.energy.2012.08.002), 2012. 
solar field consists of the field of solar collectors, plus the primary heat-transfer loop and its circulation pump, plus the buffer tank for storing heat at high temperature (hot storage) when it exists. The sub-system called chiller consists of the chiller itself, plus the system for rejecting heat to the ambient air, most often a cooling tower, plus the heat-transfer loop between these two, plus the buffer tank for storing cold at low temperature (cold storage) when it exists. The interface between the two sub-systems is the hot heat-exchanger of the chiller itself. Denoting by $\dot{Q}_{h}$ (in $\mathrm{kW}$ ) the heat flux received by the chiller from the solar field, then the average heat quantity transferred per day and per unit area of the collector field is:

$$
\overline{q_{h}}=\frac{1}{N_{d} \cdot A_{s C}} \sum_{n}\left[\int_{\text {day\#n }} \dot{Q}_{h}(t) \cdot \mathrm{d} t\right]
$$

The average collecting efficiency and average chiller-COP are straightforwardly defined as:

$$
\begin{gathered}
\overline{\eta_{s f}}=\overline{q_{h}} / \overline{q_{s o l}}, \\
\overline{C O P_{c h}}=\overline{q_{a c}} / \overline{q_{h}}
\end{gathered}
$$

\subsubsection{One-day performance}

Most of the time, performance of solar-powered chillers reported in the literature are evaluated for few individual days only. Are they representative of long-term performance? In order to address this issue, one day was selected in the operation period of each unit with only one common constraint: daily insolation was to be close to $6.0 \mathrm{kWh}_{\mathrm{d}} \cdot \mathrm{m}^{-2}$. This value was chosen because it corresponds to a rather bright day while being significantly lower than the maxima of insolation (typically in the range $7-7.6 \mathrm{kWh}_{\mathrm{d}} \cdot \mathrm{m}^{-2}$ ). It can be expected that imposing a common daily insolation would cancel the effects of local climate. Indeed, the climatic statistics are quite different between the five test places. Applying the same procedure as above for one single day denoted by number $m$ and leads to the following three figures:

$$
\begin{gathered}
C O P_{\text {sol }, 1 d}=\frac{\int_{\text {day\#m }} \dot{Q}_{a c}(t) \cdot \mathrm{d} t}{A_{s c} \cdot \int_{\text {day\#m }} \dot{q}_{\text {sol }}(t) \cdot \mathrm{d} t} \\
\eta_{s f, 1 d}=\frac{\int_{\text {day\#m }} \dot{Q}_{h}(t) \cdot \mathrm{d} t}{A_{s c} \cdot \int_{\text {day\#m }} \dot{q}_{\text {sol }}(t) \cdot \mathrm{d} t} \\
C O P_{\text {ch, }, 1 d}=\frac{\int_{\text {day\#m }} \dot{Q}_{a c}(t) \cdot \mathrm{d} t}{\int_{\text {day\#m }} \dot{Q}_{h}(t) \cdot \mathrm{d} t}
\end{gathered}
$$

These three figures will be compared to the corresponding average values. As Syed et al. [10] made the same comparison their results are also reported herein.

Pons M., Anies G., Boudehenn F., Bourdoukan P., Castaing-Lasvignottes J., Evola G., Le Denn A., Le Pierrès N., Marc O., Mazet N., Stitou D., and Lucas F., Performance comparison of six solarpowered air-conditioners operated in five places, Energy, 46, pp.471-483 (DOI: 10.1016/j.energy.2012.08.002), 2012. 


\section{The solar air-conditioners tested in the project}

The six units in test are located in five places in France with various climates, see Fig. 1. Perpignan (lat. $43^{\circ} 42^{\prime} \mathrm{N}$, units Solaclim and Climsol) is very close to the Mediterranean Sea, when La Rochelle lies on the Atlantic coast (lat. $46^{\circ} 09^{\prime} \mathrm{N}$, unit Desic). Both Le Bourget du Lac (lat. $45^{\circ} 39^{\prime} \mathrm{N}$, unit Solera) and Pau (lat. $43^{\circ} 18^{\prime} \mathrm{N}$, unit Aquisol) are at low altitude (200$250 \mathrm{~m}$ ), the former in the Alps, the latter in the Pyrenees and close to the Atlantic Ocean. Lastly Saint-Pierre de La Réunion (lat. $21^{\circ} 18^{\prime} \mathrm{S}$, unit Rafsol) lies the French tropical island La Réunion, in the South-West of the Indian Ocean.

One unit (Climsol) is completely experimental, but all the other ones are built-up with commercial components. Except for one (Desic), which is based on open desiccant cycle, the units use closed sorption chillers, and can be globally described by the sketch-up of Fig. 2: flat-plate thermal collectors A (no photovoltaic, no tracking, non-focusing concentration if any), buffer tank B for hot storage, chiller C, buffer tank D for cold storage and cold distribution loop E. These components are connected by heat-transfer loops shown and numbered in Fig. 2. One of the two storages B and D may be optional. Rejection toward the environment of the heat released by the condenser and absorber may be done via a cooling tower $\mathrm{E}$ or via a ground heat-exchanger F. Most of the units are equipped with only one of them, while the unit Climsol uses a heat-exchanger naturally cooled by air plus a water-toground heat-exchanger connected in series. Two units, Solaclim and Climsol, use solid sorption in closed alternate cycle, respectively adsorption and thermochemical reaction. The three other units (Solera, Rafsol, Aquisol) use liquid sorption with continuous cycle. The fundamental differences of principle between liquid sorption chillers (Solera, Rafsol, Aquisol), solid sorption chillers (Solaclim and Climsol) and desiccant-wheel chillers (Desic) are presented in Fig. 3. With liquid sorption, absorption and desorption (vapor generation) occur in specific components. With solid sorption, they may occur in the same component when the cycle is 24-hour long.

The main technical characteristics of the six units are gathered in Table 1: solar collectors (area, type and manufacturer), chiller (type, nominal cooling power and manufacturer), hot and cold storages (size and material), and means for rejecting heat to the environment. Relevant additional features which are specific to each unit are given in the following subsections. All the six units are sufficiently instrumented for correctly evaluating the heat fluxes

$\dot{q}_{s o l}, \dot{Q}_{h}$ and $\dot{Q}_{a c}$ : pyranometers for incident global insolation on the collectors' plane, inlet and outlet temperature probes and flowmeters for heat balances at each of the components described in Fig. 2, indoor and outdoor temperatures, pressure gauges when necessary, especially for security. Total electricity consumption of the units in nominal operation is also monitored. Commercial components, such as some chillers or the solar collectors, were hardly modified, so that internal data (temperature, pressure, composition) were not available.

\subsection{SOLACLIM: solid sorption cycle, by TECSOL and PROMES}

In closed cycles with solid adsorption, heating and cooling periods alternate. As the unit (Sortech ACS 08) has two adsorbers operated out-of-phase, the cold production is almost continuous. The adsorbent is silicagel, the refrigerant water, and the cycle period is of the order of 10-15 mn. The chiller operates at pressures below atmospheric.

The Solaclim unit is designed for refreshing the office building of the PROMES laboratory (cooling in summer, heating in winter). The flat-plate collectors are installed on the

Pons M., Anies G., Boudehenn F., Bourdoukan P., Castaing-Lasvignottes J., Evola G., Le Denn A., Le Pierrès N., Marc O., Mazet N., Stitou D., and Lucas F., Performance comparison of six solarpowered air-conditioners operated in five places, Energy, 46, pp.471-483 (DOI: 10.1016/j.energy.2012.08.002), 2012. 
building roof. The heat they supply can be either stored in a buffer tank or directly transferred to the chiller. The heat flux released by the adsorption chiller is rejected via a drycooler with water aspersion also installed on the roof. The solar primary loop (\#1 in Fig. 2) is protected from overheating by drainback procedure (the circuit is emptied when too hot).

The unit is equipped with temperature sensors (Pt1000 class B) and water flow-meters (mechanical type, class B); the data are recorded every 10 minutes.

\subsection{Liquid sorption chillers $(\mathrm{LiBr}+$ water $)$}

Liquid sorption chillers are commercialized for decades [26]; their cycle is closed and continuous. Three units (Solera, Rafsol and Aquisol) use single-effect absorption chillers with the sorption pair $\mathrm{LiBr}+\mathrm{H}_{2} \mathrm{O}$. Like Solaclim, they operate at under-atmospheric pressures.

\subsubsection{SOLERA, by CEA INES and LOCIE}

The Solera unit, located in Le Bourget du Lac (France), is a small-scale unit $(4.5 \mathrm{~kW}$ cold) designed for refreshing three office rooms $\left(63 \mathrm{~m}^{2}\right)$ [27]. The flat- plate solar collectors (Clipsol TGD-th) are implemented on the building roof, facing South with a tilt angle of $30^{\circ}$, and arranged in two rows. Here the primary solar loop (\#1 in Fig. 2) is split in two parts separated by a compact brazed-plate heat-exchanger (CIAT). The solar-heat storage is a Solar CombiSystem (SCS, Clipsol Blocsol-CombiRSD-120, see Table 1) the electronics of which are used also for controlling the whole unit. The chiller is a Rotartica model 045. Heat is rejected toward the environment via a ground heat exchanger ( 22 horizontal probes, $0.75 \mathrm{~m}$ or $1.1 \mathrm{~m}$ deep, about $100 \mathrm{~m}$ long), a system that limits electricity consumption and does not consume any water. The cold storage delivers cold water to 6 high-efficiency fan-coils Coadis (CIAT). The monitored data are averaged over two minutes before being recorded.

\subsubsection{RAFSOL, by PIMENT}

The Rafsol unit is designed for refreshing four classrooms without any backup systems (hot or cold) under a tropical climate. Thirty-six flat-plate solar collectors are installed on the building roof. In nominal conditions the absorption chiller receives heat at $90^{\circ} \mathrm{C}$, releases heat at $30^{\circ} \mathrm{C}$ and produces cold at $11^{\circ} \mathrm{C}$. The cooling tower (VXT025, by BAC) is of the open type (the water circuit denoted as \#5 in Fig. 2 is open; the warm water it contains can evaporate, enhancing thus heat release to outdoor air) and is equipped with a centrifugal fan. The nominal power rate of heat rejection, $80 \mathrm{~kW}$, is obtained with water at $36^{\circ} \mathrm{C}$, outdoor air at $30^{\circ} \mathrm{C}$ and the nominal air flow-rate of $2.5 \mathrm{~m}^{3} . \mathrm{s}^{-1}$. In such conditions, the electrical power of the fan is $2.6 \mathrm{~kW}$, to which must be added $1.8 \mathrm{~kW}$ for the pump circulating water between the chiller and the cooling tower. Cold is distributed to fan-coils in four classrooms via a hydraulic circuit. Special care was given to the thermal coupling with the building, so that non-conventional comfort conditions are obtained: indoor air is maintained at $6^{\circ} \mathrm{C}$ below the outdoor temperature [28, 29].

\subsubsection{AQUISOL, by LaTEP}

This small-scale experimental unit, tested in Pau see Fig. 1, is designed for refreshing two climatic rooms ( $15 \mathrm{~m}^{2}$ each) where cooling demand is simulated. Each room is equipped with a fan-coil. The field of solar collectors consists of $12.4 \mathrm{~m}^{2}$ of evacuated-tube collectors with low concentration (Tecnisun) plus $4.2 \mathrm{~m}^{2}$ of evacuated-tube collectors without concentration (Viessmann). Heat transfer from solar absorber to heat transfer fluid is done, either through

Pons M., Anies G., Boudehenn F., Bourdoukan P., Castaing-Lasvignottes J., Evola G., Le Denn A., Le Pierrès N., Marc O., Mazet N., Stitou D., and Lucas F., Performance comparison of six solarpowered air-conditioners operated in five places, Energy, 46, pp. 471-483 (DOI: 10.1016/j.energy.2012.08.002), 2012. 
heat-pipes (Tecnisun), or directly (Viessmann). All the collectors are connected in series; they are installed at the ground level, and oriented South with a tilt angle that can be adjusted from 30 to $60^{\circ}$. The hot water buffer tank directly exchanges fluid with the primary loop and with the secondary loop connected to the chiller's generator. The absorption chiller is the Rotartica model 045.

\subsubsection{UC3M, by University Carlos III Madrid}

The unit tested in Univ. Carlos III Madrid CSIC is also based on liquid sorption and can really be compared to the units tested herein, see Table 2 . More details can be found in [10, 11]. Their chiller is unfortunately over-sized for the cooling demand $(35 \mathrm{~kW}$ vs. $3 \mathrm{~kW}$ cooling), which leads to sub-optimal performance.

\subsection{DESIC, open sorption cycle by LEPTIAB}

In desiccant chillers, humid air is the working fluid [30]. The cycle is open, sorption occurs in a desiccant rotary wheel. Cooling is obtained by humidification of previously dried air, these units thus steadily consume liquid water. On the other hand, they handle both temperature and humidity content of fresh supply air, and indoor air is altogether renewed. Such units operate at atmospheric pressure. They do not reject heat to the environment but warm humid air. Therefore such units have no cold storage nor heat rejection system.

The desiccant system Desic tested in La Rochelle is purely experimental and is not coupled to any real building. The solar collectors are installed on the building's façade, oriented South, see Table 1. The air-handling unit itself (manufactured by ProFlute and CIAT) consists of a silicagel desiccant wheel, a regeneration heat exchanger, a sensible heat regenerator, two centrifugal evaporative coolers, and two fans. The dimensions are $6.35 \mathrm{~m}$ long $\times 1.52 \mathrm{~m}$ large $\times 2.1 \mathrm{~m}$ high; the weight is of $1500 \mathrm{~kg}$. The nominal air flow-rate is of $3000 \mathrm{~m}^{3} \cdot \mathrm{h}^{-1}$. Prescribed outdoor air conditions (temperature, humidity) can be simulated by pre-treatment in an air-handling unit up-hill the desiccant system. The cooling load is produced by a computer-driven electrical heater that mimics the load of $250 \mathrm{~m}^{2}$ offices. The offices are numerically simulated with the TRNSYS software with the climate of a hot sunny summer day in La Rochelle. The details of this simulation (occupancy, consumption of appliances, conduction coefficient of the walls and windows, transmittance of glazing, etc.) are given by Bourdoukan et al. [31,32]; it can be mentioned that the cooling load could be as high as $7.3 \mathrm{~kW}$.

Instrumentation of this unit strongly differs from that on the other units. In addition to solar radiation, temperatures, pressures, and water flow rates, are also measured humidity ratio, and air flow rates. Our definition of the cooling capacity of the desiccant unit is based on thermodynamic considerations: this is the amount of heat removed from the building, i.e. the enthalpy difference between the air supplied to and the return air removed from the simulated 'building'. The electrical power-rate for driving the auxiliaries (fans, rotating wheels and evaporative coolers) is of $1.25 \mathrm{~kW}$.

\subsection{CLIMSOL, thermochemical solid sorption by PROMES}

Thermochemical systems involve a chemical reaction between a gas and a salt in solid state [33]. The working pair used in the unit Climsol is ammonia plus barium chloride $\mathrm{BaCl}_{2}$, with which decomposition can occur around $50-70^{\circ} \mathrm{C}$ when ammonia vapor condenses at ambient temperature. Such a low decomposition temperature is the main advantage of that

Pons M., Anies G., Boudehenn F., Bourdoukan P., Castaing-Lasvignottes J., Evola G., Le Denn A., Le Pierrès N., Marc O., Mazet N., Stitou D., and Lucas F., Performance comparison of six solarpowered air-conditioners operated in five places, Energy, 46, pp.471-483 (DOI: 10.1016/j.energy.2012.08.002), 2012. 
pair. The thermodynamic cycle operates discontinuously with the alternation of two phases over a cycle of 24 hours. During the day, the salt is regenerated by solar heat and ammonia is condensed; during the night, the heat released by the salt is rejected to the environment while ammonia evaporates, thus extracting heat at low temperature. As the cooling effect occurs only at night, a cold storage is required for refrigeration to be delayed until the next day. The pilot plant is designed for providing $20 \mathrm{kWh}$ cold each day, from which a conference room of $120 \mathrm{~m}^{2}$ can be refreshed.

All the components described in Fig. 2 are present in the unit Climsol, see also Table 1. The flat plate collectors (Helioakmi ST2000) are tilted at $30^{\circ}$ and oriented toward South. The hot heat-storage is filled with $360 \mathrm{~kg}$ phase change material (RT80 wax with melting point at $75-80^{\circ} \mathrm{C}$ manufactured by Rubitherm $\mathrm{GmbH}$ ) mixed with $20 \mathrm{~kg}$ expanded natural graphite (ENG), an additive used for enhancing heat transfer. The thermochemical chiller strongly differs from liquid sorption ones. It consists of four components: (i) the thermochemical reactor (500 liters), filled with a reactive composite associating anhydrous $\mathrm{BaCl}_{2}(140 \mathrm{~kg})$ and ENG (35kg); (ii) the condenser to which the reactor is connected during the day; (iii) a tank (100 liters) for storing the liquid ammonia formerly condensed (up to 65kg) before the ammonia is transferred into the evaporator; (iv) the evaporator to which the reactor is connected during the night. The heat rejection toward the environment, condensation heat during the day, heat released by the reactor during the night, is done via a heat-exchanger cooled by outdoor air $\left(52 \mathrm{~m}^{2}\right.$, no fan) and a ground heat-exchanger $\left(16 \mathrm{~m}^{2}\right.$, two meter deep), connected in series (loops \#5 and \#6 of Fig. 2). Ammonia evaporation at night produces cold at temperatures between 0 and $5^{\circ} \mathrm{C}$. This cooling capacity is stored, via a loop of chilled water (\#3), into a cold storage filled with $380 \mathrm{~kg}$ Rubitherm RT5 (phase change material with melting point at $5^{\circ} \mathrm{C}$ ) mixed with $20 \mathrm{~kg}$ ENG. During the day, distribution of fresh water (loop \#4) in the fan-coils of the conference room is activated on users' demand. The water temperature in loop \#4 usually lies around $13-14^{\circ} \mathrm{C}$.

The unit is fully instrumented, including level gauges for liquid ammonia in the condenser tank and in the evaporator. Data are monitored using a data acquisition software developed in PROMES under Labview ${ }^{\circledR}$. This software also controls the unit. Circulation in the primary loop (\#1 in Fig. 2) is controlled using data on insolation and temperature of the heat transfer fluid in various points (solar collectors, reactor and hot storage). The valves between the reactor and either the condenser or the evaporator are controlled using data on the liquid levels and pressures in the reactor, evaporator and condenser. More details on this novel solid/gas sorption solar air-conditioner, its operation, and specific analysis of its performance are given by Stitou et al. [34].

\section{Results and discussion}

The experimental values of the figures of merit introduced in section 2 are gathered in Table 3. The whole set is rich of information, addressing issues rarely addressed in the literature, such as reasonably expectable performance from the present technologies, aging, or auxiliary consumptions (electricity and water).

\subsection{Average solar COP}

Considering all the results globally, the average solar COP is of the order of 0.1 , but a maximum value of 0.2 was reached for two units. Leaving aside the two large values around 0.2 that will be commented further on, the global result can be analyzed in more details.

Pons M., Anies G., Boudehenn F., Bourdoukan P., Castaing-Lasvignottes J., Evola G., Le Denn A., Le Pierrès N., Marc O., Mazet N., Stitou D., and Lucas F., Performance comparison of six solarpowered air-conditioners operated in five places, Energy, 46, pp. 471-483 (DOI: 10.1016/j.energy.2012.08.002), 2012. 
First, it can be seen that the values of $\overline{C O P_{\text {sol }}}$ lie in a rather narrow range [0.08-0.13]. However, this narrowness results from the combined effects of two large scatters, that on the collecting efficiency $\overline{\eta_{s f}}[0.14-0.4]$, and that on the chiller-COP $\overline{C O P_{c h}}$ [0.2-0.7]. Although some parameters may influence both $\overline{\eta_{s f}}$ and $\overline{C O P_{c h}}$ in opposite directions (e.g. the maximal

fluid temperature in the hot storage), it can reasonably be inferred that an average collecting efficiency of 0.3 and an average chiller-COP of 0.6 are both in reach with the technologies tested in this project. It can then be said that an average solar COP of 0.18 can be obtained with the current technologies. As a matter of fact, values of 0.19 and 0.20 were actually measured with two units, at least for one year.

Secondly, performance can be severely downgraded from the first operation year to the second, as was the case for the Rafsol unit (-30\%). The main responsible is the average collecting efficiency $\overline{\eta_{s f}}$, which dropped dramatically in just one year. Actually, three aging scenarios were observed in the project; they are presented in the next sub-section. This means that aging of the solar primary loop remains a complex problem, even for commercial components of good quality. Oppositely, performances of the chillers were intrinsically fairly stable in time; the COP of the Climsol chiller was even improved between the first and second year after a change in the operation procedure. This result shows that adapting the control procedures of commercial chillers to the features of solar energy could enhance performance.

Thirdly, chillers with continuous cycles are averagely more efficient than those with discontinuous cycles: $\overline{C O P_{c h}}$ of 0.55-0.7 instead of 0.25-0.3 for Solaclim and Climsol. This experimental result confirms a former numerical comparison of sorption chillers [35]. There are objective reasons for that difference: in discontinuous cycles, the reactor containing the active material (in the present cases silicagel or $\mathrm{BaCl}_{2}+\mathrm{ENG}$ composite) must be heated up to the operation temperature at each cycle. The heat supplied to inert materials (metallic envelop, heat exchangers, heat transfer fluid, etc.) does not contribute to the cooling process itself, but must be anyhow supplied. On the opposite in continuous cycles, once each component has reached its operation temperature the only heat to be supplied is for the active material $(\mathrm{LiBr}$ solution). In addition, efficient internal heat recovery is easier to implement in continuous cycles. However, there are other points of view from which discontinuous cycles offer more advantages than continuous ones.

\subsection{Three aging scenarios}

\subsubsection{For the Solera unit}

From the first test year to the second, the needs in air-conditioning in the offices were strongly reduced because of two phenomena. First, insolation during the second year was weaker. Moreover, a new building was erected on the South side of the test building; that new building significantly casts a shadow on the three offices air-conditioned by the unit. Both effects significantly reduce the cooling demand. With a the lower cooling demand, the heat withdrawn from the hot storage is significantly reduced, making the measured average temperature in the solar collectors increase by more than $15 \mathrm{~K}$ from one year to the next. This temperature increase significantly reduces the efficiency of the collectors. In this case, aging means that the solar air-conditioning unit became oversized because of changes in the

Pons M., Anies G., Boudehenn F., Bourdoukan P., Castaing-Lasvignottes J., Evola G., Le Denn A., Le Pierrès N., Marc O., Mazet N., Stitou D., and Lucas F., Performance comparison of six solarpowered air-conditioners operated in five places, Energy, 46, pp.471-483 (DOI: 10.1016/j.energy.2012.08.002), 2012. 
surroundings of the building. In this new configuration, part of the incident solar flux must be dissipated without producing cold.

\subsubsection{For the Rafsol unit}

Here again some changes were done between the first and second test years: the flow-rate in the primary solar loop was reduced by $13 \%$ for the sake of experimentation. Obviously, this change tends to increase the fluid temperature in the collectors, and thus to reduce the efficiency of the latters. However, the major factor probably lies in total electrical breakdowns. Indeed as La Réunion is a relatively small island, the electrical network is limited in size and forcedly autonomous and isolated. It is thus fragile and electricity supply undergoes complete stops several times a year. When such a failure occurs at daytime, circulation in the primary loop stops and temperature in the solar collectors rises rapidly. Such uncontrolled temperature excursions result in overheating, irreversible damages, and finally reduction in collector efficiency. Corrosion by the salty moisture in the atmosphere of SaintPierre (close to the sea shore, the air is loaded with seawater spray) might also cause degradation, but the decrease would be more steady along the years.

\subsubsection{For the Climsol unit}

It is observed here that the solar collectors were significantly damaged from the first to the second year. It is not clear whether this degradation is due to overheating during wintertime, when insolation is not negligible while the unit is unused, or to an intrinsically low quality of the collectors themselves.

It can be concluded from these aging scenarios that protection against overheating is crucial for maintaining the collectors at high performance at long term.

\subsection{Average electricity consumption}

The electricity consumptions recorded for each unit are given in Table 3, they range from 0.17 to 0.35 electrical $\mathrm{kWh}$ per kWh cooling, except for the Aquisol unit where a problematic pressure drop has been now identified as accidental. Those figures must be compared to 0.410.42 , accepted as seasonal electricity consumption for compression air-conditioning [36, 37]. Solar-powered air-conditioners do consume less electricity than compression ones, nevertheless their electricity consumption at their current stage of development is not negligible at all, a point rarely mentioned in the literature. Analysis showed that electricity consumption is mainly due to the heat rejection loop, via (i) the circulation pump (\#5 in Fig. 2) from the chiller and the cooling tower, and (ii) the fans for forcing convection on the cooling tower (E in Fig. 2). For instance, these two items are responsible for $60 \%$ of the total electricity consumption of the unit Rafsol. The electricity consumed for circulating the heattransfer fluid in the primary solar loop (\#1 in Fig. 2), and by the chiller itself ( $\mathrm{C}$ in Fig. 2), is not necessarily negligible but remains less than the former one. Note that for the desiccant unit Desic, the electricity budget is quite different: there is no cooling tower (warm humid air is rejected outdoor), but there are instead fans for the supply and return air streams, motors for rotating the two wheels, and the system for spraying liquid water into the evaporative coolers.

The development of solar-powered air-conditioning would be severely handicapped by too large an electricity consumption, it is therefore important to analyze more finely the figures given in Table 3. First, one must be aware that heat-powered chillers reject more heat than compression-driven ones for a given cooling-load. The reason is simply thermodynamic:

Pons M., Anies G., Boudehenn F., Bourdoukan P., Castaing-Lasvignottes J., Evola G., Le Denn A., Le Pierrès N., Marc O., Mazet N., Stitou D., and Lucas F., Performance comparison of six solarpowered air-conditioners operated in five places, Energy, 46, pp.471-483 (DOI: 10.1016/j.energy.2012.08.002), 2012. 
if $Q_{a c}$ is the amount of cold produced by the chiller, then the amount of heat to be rejected to the environment is $Q_{a c} \cdot\left(1+1 / \overline{C O P_{c h}}\right)$, which is the sum of the cold production plus the power energy. The ratio $\left(1+1 / \overline{C O P_{c h}}\right)$ lies around 1.4 for a compression air-conditioner $(0.4$ $\mathrm{kWh}$ electricity for $1 \mathrm{kWh}$ cooling) when it lies between $2.7\left(\overline{C O P_{c h}}=0.6\right)$ and 5 $\left(\overline{C O P_{c h}}=0.25\right)$ for the sorption chillers tested in this study. More heat to be rejected by the cooling tower means larger heat exchange surface, larger fans in the tower, and stronger pumps for the heat-rejection loop (\#5 in Fig. 2). However, this conclusion is moderated by a feature which is especially favorable to discontinuous cycles operated on a 24-hour period, like on the Climsol unit. Indeed, such cycles reject heat in the daytime (condensation) and also at night-time (cooling of the reactor). Both the longer duration of heat transfer and the cooler outdoor air at night favor heat-rejection and thus tend to reduce the total electricity consumption. This basic feature partly explains the relatively low electricity consumption of the Desic unit. Moreover, part of the heat rejected by the chiller is transferred to the environment by a water-to-ground heat exchanger, which complements in series the cooling tower. This arrangement also contributes to the low electricity consumption. On the opposite, on the Rafsol unit the cooling tower is about $100 \mathrm{~m}$ away from the chiller. This long distance, plus the fact that the heat-rejection loop is of the open type, both contribute to the large electricity consumption.

As a conclusion, with the current technologies one can expect an electricity consumption of $0.2-0.5 \mathrm{kWh}$ per $\mathrm{kWh}$ cold. The design of the cooling tower and rejection loop are of special importance for reducing that consumption.

\subsection{Average consumption of water}

In the context of sustainability of energy processes, any kind of footprint, energy or matter, must be considered. This is why the authors decided to also report on the amount of water consumed by each unit. This point may be important in the many places where cleanwater supply is limited or non-reliable. The closed sorption cycles (units Solaclim, Solera, Rafsol, Aquisol and Climsol) do not consume liquid water by their principle, but wet cooling towers do. This is why the units Solaclim and Rafsol do consume water. Moreover, the open character of the heat-rejection loop of the unit Rafsol makes this unit consume quite a large amount of water, which is not beneficial and could be avoided with another design. On the opposite, the water consumption of the Desic unit is intrinsic: by their principle, desiccant open cycles produce cold in the two humidifiers, by evaporating sprays of liquid droplets.

\subsection{Comparison with performance on one day}

The last three lines of Table 3 show the values of solar COP, collecting efficiency and chiller COP that would have been reported if only one day with given insolation had been retained for the comparative analysis. The general trend is interesting to note: performance evaluated on one single day over-estimates seasonal performance by a factor 1.2-1.6 (see Fig. 4). The group from Madrid also reports similar over-estimation [10].

\section{Single-day performance versus seasonal performance}

Table 3 shows that single-day performance is over-evaluated compared to seasonal performance. Is that overestimation due to an uncontrolled bias or to some systematic effect? The issue is addressed here-under following a theoretical analysis.

Pons M., Anies G., Boudehenn F., Bourdoukan P., Castaing-Lasvignottes J., Evola G., Le Denn A., Le Pierrès N., Marc O., Mazet N., Stitou D., and Lucas F., Performance comparison of six solarpowered air-conditioners operated in five places, Energy, 46, pp.471-483 (DOI: 10.1016/j.energy.2012.08.002), 2012. 
First of all, the last two lines of Table 3 show that the over-estimation is more largely due to the solar-field efficiency $\eta_{s f}$ than to the chiller-COP COP $c h$. The analysis focuses on that efficiency; it relies on (i) a theoretical description of the operation of the tested solar units with three procedures each day, (ii) some assumptions, and (iii) a model two experimentallybased parameters. Are considered the thermal states of the solar field at given moments, where the thermal state means the temperature field $T(\mathbf{r})$, where $\mathbf{r}$ is the position in the solar field, and various heat quantities and heat-fluxes related to those thermal states.

\subsection{Theoretical description of the operation}

Daily operation of solar solar-powered chiller based on liquid sorption, desiccant cooling, or solid sorption with short cycles, can globally be described as a succession of three procedures, which are presented in Fig. 5.

Procedure \#1: thermal conditioning of the solar field from sunrise (moment $t_{\# 1}$ ) to the moment $t_{\# 2}$ when the thermal state of the solar field is sufficient for heat to be transferred to the chiller. During this first procedure, the primary heat-transfer fluid is circulated in the solar loop but the chiller remains switched-off. The solar flux is then accumulated into the solar field for making it change from the thermal state it has at sunrise to the thermal state required for switching-on the chiller, respectively $T_{\# 1}(\mathbf{r})$ and $T_{\# 2}(\mathbf{r})$. This procedure takes some time during which dissipation also occurs. As a result, the major part of the incident solar energy during this procedure is accumulated into the solar field, while the complement is dissipated toward the atmosphere. The total energy so-involved, $Q_{s \# 1}$, is written:

$$
Q_{S \# 1}=\int_{\text {solar field }} \rho(\mathbf{r}) \cdot c_{p}(\mathbf{r}) \cdot\left[T_{\# 2}(\mathbf{r})-T_{\# 1}(\mathbf{r})\right] \cdot \mathrm{d} v+\int_{t_{\# 1}}^{t_{\# 2}} \dot{Q}_{d}(t) \cdot \mathrm{d} t
$$

Procedure \#2: normal operation of the solar field and chiller, from the moment $t_{\# 2}$ and as long as heat can be transferred to the latter, with cold production by the chiller. This procedure takes end at the last moment before sunset, $t_{\# 3}$, when insolation compensates the thermal dissipation of the solar field. During this procedure, the heat transferred to the chiller equates at the first order the difference between global insolation and dissipation when positive. Time integration of the transferred heat-rate is written:

$$
Q_{S \# 2}=\int_{t_{\# 2}}^{t_{\# 3}} \delta \cdot\left(A_{\text {sC }} \cdot \dot{q}_{s o l}(t)-\dot{Q}_{d}(t)\right) \cdot \mathrm{d} t
$$

with $\delta=1$ when $A_{s c} \cdot \dot{q}_{s o l}(t)>\dot{Q}_{d}(t)$; and $\delta=0$ otherwise. It will be shown later on that $Q_{\mathrm{s} \# 2}$ corresponds to the quantity introduced as $\int_{d a y} \dot{Q}_{h}(t)$.d $t$ in Section 2.2.3.

Procedure \#3: after moment $t \# 3$ and during the night, the solar field can no longer supply heat at sufficient temperature to the chiller. Both are switched off, and the temperature field in the whole unit undergoes thermal relaxation by heat dissipation toward the ambient air. The corresponding heat will need to be supplied again in the next procedure \#1. Fig. 5 graphically shows that $Q_{\mathrm{s} \# 2}$ is a non-linear function of total insolation.

Pons M., Anies G., Boudehenn F., Bourdoukan P., Castaing-Lasvignottes J., Evola G., Le Denn A., Le Pierrès N., Marc O., Mazet N., Stitou D., and Lucas F., Performance comparison of six solarpowered air-conditioners operated in five places, Energy, 46, pp.471-483 (DOI: 10.1016/j.energy.2012.08.002), 2012. 


\subsection{Assumptions}

\subsubsection{About heat storage}

The three procedures described above do not consider any storage effect, although a hot storage is implemented on each unit between the solar loop and the chiller. This hot storage is used for de-correlating heat transfer to the chiller from insolation, and thus smoothing the fluctuations of the latter. At first sight, the presence of this hot storage should significantly change the description of the three procedures. However, when thinking in terms of energy integrated over whole days, and when assuming that the hot storage is perfect (no dissipation) and balanced (the heat delivered averagely equates the heat stored), then it can be deduced that the hot storage does not change the total quantity of heat transferred from the solar field to the chiller. The equations (10) and (11) thus correctly yield the energies involved in the daily operation.

\subsubsection{About thermal state during procedure \#2}

The next issue is: are the thermal states at moments $t_{\# 2}$ and $t \# 3$ different from each other? Does sensible energy contained in the solar field change significantly during procedure \#2 compared to the energy $Q_{s \sharp 2}$ given by equation (11)? Is the following inequality satisfied?

$$
\int_{\text {solar field }} \rho(\mathbf{r}) \cdot c_{p}(\mathbf{r}) \cdot\left[T_{\# 3}(\mathbf{r})-T_{\# 2}(\mathbf{r})\right] \cdot \mathrm{d} v \ll Q_{S \# 2}
$$

Considering that at both moments $t_{\# 2}$ and $t_{\# 3}$ the thermal state of the solar field is just sufficient for usefully transferring heat to the chiller, it is reasonable to assume that both thermal states are rather close to each other and consequently that the inequality (12) is true.

It can also be assumed that those two thermal states do not significantly change from one day to another. Indeed, the heat-rate transferred from the solar field to the chiller and the return temperature of the heat-transfer fluid in the solar loop, either at $t_{\# 2}$ or at $t_{\# 3}$, are approximately the same every day, because they are prescribed by operational conditions of the chiller itself (e.g. nominal inlet temperature and minimal power-rate). Consequently, the sensible heat involved in the daily fluctuations in the thermal states $T_{\# 2}(\mathbf{r})$ and $T_{\# 3}(\mathbf{r})$ is small

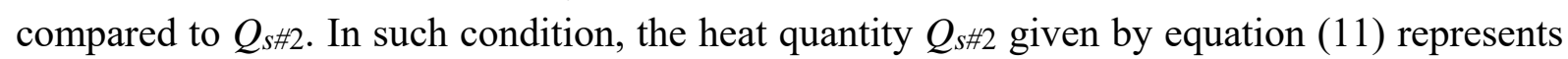
the total heat quantity transferred from the solar field to the chiller, $Q_{h}$.

\subsubsection{About thermal relaxation during procedure \#3}

As shown in the previous section, it can be assumed that the thermal state $T_{\# 3}(\mathbf{r})$ is approximately the same every day. In addition, the application of the present solar units is airconditioning; this means that they are used during the part of the year when the outdoor temperature lies above the comfort conditions. When considering now the time function of the outdoor temperature during the nights of the air-conditioning season in a given place, some scatter surely occurs from one day to another, but the magnitude of this scatter can reasonably be assumed small compared to the magnitude of the difference between the two thermal states $T_{\# 3}(\mathbf{r})$ and $T_{\# 1}(\mathbf{r})$. In other words, the notion of average outdoor conditions can be used for describing thermal relaxation during procedure \#3. Adding now the date-independence of the thermal state $T_{\# 3}(\mathbf{r})$, it can be concluded that the thermal state at sunrise, $T_{\# 1}(\mathbf{r})$, is approximately the same every day.

Pons M., Anies G., Boudehenn F., Bourdoukan P., Castaing-Lasvignottes J., Evola G., Le Denn A., Le Pierrès N., Marc O., Mazet N., Stitou D., and Lucas F., Performance comparison of six solarpowered air-conditioners operated in five places, Energy, 46, pp.471-483 (DOI: 10.1016/j.energy.2012.08.002), 2012. 


\subsection{Presentation of the model}

The assumptions above imply that the heat-quantity $Q_{\mathrm{s} \# 1}$ involved in procedure \#1 and the dissipation rate $\dot{Q}_{d}(t)$ involved in procedure \#2 are approximately the same every day. This leads to our model. In order to avoid confusion with the description of the real operation, this model is presented in terms of daily energy or of power-rate per square meter of solar collector $\left[\mathrm{kWh} \cdot \mathrm{m}^{-2}\right.$ or $\left.\mathrm{kW} \cdot \mathrm{m}^{-2}\right]$. By convention the superscript $*$ denotes quantities which are calculated by the model, when the other ones are experimental.

Procedure \#1: After sunrise (moment $t_{\# 1}$ ), the solar flux first provides the solar field with a total heat quantity $\overline{q_{S \# 1}}$ which is the same every day. For each day a moment $t_{\# 2}^{*}$ is thus calculated that fulfills the condition:

$$
\int_{t_{\# 1}}^{t_{\# 2}^{*}} \dot{q}_{s o l}(t) \cdot \mathrm{d} t=\overline{q_{S \# 1}}
$$

At this moment $t_{\# 2}^{*}$, the thermal state of the solar field is expected to be such that heat can be transferred to the chiller. Procedure \#2 can start.

Procedure \#2: From $t_{\# 2}^{*}$ to $t_{\# 3}^{*}$, heat can be supplied to the chiller under the condition that the solar flux $\dot{q}_{s o l}(t)$ lies over the average dissipation rate $\overline{\dot{q}_{d}}$. Integration yields an evaluation of the heat transferred to the chiller that day, $q_{h}^{*}$ :

$$
q_{h}^{*}=\int_{t_{\# 2}^{*}}^{t_{\# 3}^{*}} \delta \cdot\left(\dot{q}_{s o l}(t)-\overline{\dot{q}}_{d}\right) \cdot \mathrm{d} t \text {; with } \delta=1 \text { when } \dot{q}_{\text {sol }}(t)>\overline{\dot{q}_{d}} \text {; and } \delta=0 \text { otherwise }
$$

where $t_{\# 3}^{*}$ is the moment of the considered day when the solar flux becomes definitively lower than $\overline{\dot{q}_{d}}$.

This model relies on two parameters: $\overline{q_{s \# 1}}$ and $\overline{\dot{q}_{d}}$, which can be evaluated from the set of experimental data. Indeed, the experimental moments $t_{\# 2}$ and $t \# 3$ when procedure $\# 2$ begins and takes end are well-known from experimentalists: $t_{\# 2}$ is the moment when the chiller can be switched-on, $t_{\# 3}$ is the moment before sunset when the primary solar loop is switched-off. For each operation day, $q_{s \# 1}$ and $\dot{q}_{d}$ are evaluated experimentally, the former with the use of equation (10), the latter from equality with the solar flux at moment $t \# 3$. Averaging over the $N_{d}$ operation days then yields the two parameters of the model, $\overline{q_{s \# 1}}$ and $\overline{\dot{q}_{d}}$. These two parameters are specific to each tested unit.

\subsection{Study of the difference between single day and seasonal average}

Once the parameters $\overline{q_{s \# 1}}$ and $\overline{\dot{q}_{d}}$ are determined for a given unit, the integrations (13) and (14) can be done, first with the insolation data of the selected single day (daily global

Pons M., Anies G., Boudehenn F., Bourdoukan P., Castaing-Lasvignottes J., Evola G., Le Denn A., Le Pierrès N., Marc O., Mazet N., Stitou D., and Lucas F., Performance comparison of six solarpowered air-conditioners operated in five places, Energy, 46, pp.471-483 (DOI: 10.1016/j.energy.2012.08.002), 2012. 
insolation of $6 \mathrm{kWh}_{\mathrm{d}} \cdot \mathrm{m}^{-2}$ ), leading to the quantities $q_{s o l, 1 d}$ and $q_{h, 1 d}^{*}$ for this single day, second with the insolation data of the $N_{d}$ operation days, leading after averaging to the seasonal averages $\overline{q_{s o l}}$ and $\overline{q_{h}^{*}}$. This analysis has been conducted on two units: Rafsol and Solera. The working principle of the Climsol unit differs too much from the scenario considered herein (see [34]) for being correctly represented by this model, and the numbers of operation days of the units Desic and Aquisol were too low for evidencing any statistical effect. The so-obtained values of the ratios $q_{h, 1 d}^{*} / q_{s o l, 1 d}$, and $\overline{q_{h}^{*}} / \overline{q_{s o l}}$ are given in Table 4 . They are larger than the ratios $\eta_{s f, 1 d}$ and $\overline{\eta_{s f}}$ respectively, showing that the model does not completely represent reality. Nevertheless, the figures evidence a non-linear effect: the ratio $q_{h} / q_{\text {sol }}$ is not constant at all, but increases with $q_{\text {sol. }}$. This non-linear effect, which is almost as significant as the linear dependence, explains about half of the over-estimation of $\eta_{s f, 1 d}$ compared to $\overline{\eta_{s f}}$, and makes it difficult to deduce the seasonal performance from performance measured on few single days, which are mostly bright days.

This analysis also evidences an important feature, hidden before: the energy involved in the phase \#1 is a significant part of the whole daily insolation, $1.5 \mathrm{kWh} \cdot \mathrm{m}^{-2}$ compared to 6.5 7. That energy is mainly related to the thermal inertia of the solar field. Reducing that inertia could also be a good way for improving the global performance of the whole unit.

\section{Conclusion}

Six solar-powered chillers designed for refreshing buildings, based on four different technologies, were operated over whole seasons in five different places. Comparison of their experimental performance (including a seventh unit presented in the literature) shows that the current state-of-art leads to seasonal solar COP's around 0.1. However, significantly larger values $(+50 \%$ at least) reasonably seem to be in reach, first because they were actually obtained by some tested units, second because detailed analysis shows that efficiency of individual components can be improved.

Nevertheless, seasonal electricity consumption is not always negligible (of the order of 0.2-0.25 kWh per $\mathrm{kWh}$ cold). This is only half of the seasonal electricity consumption of usual compression air-conditioners reported in the literature. Auxiliaries related to heat rejection toward the environment occur to be the main causes of that electricity consumption. Consumption of liquid water can also become a concern, if ever neglected while the unit is designed. These two consumptions can be significantly reduced when the issues are addressed during the design phase. Note that the efficiency of the chiller itself is a key factor with respect to the rate of heat rejection. With respect to this point, chillers based on solid sorption cycles may need better performance. As a first conclusion, solar energy can currently be used for refreshing buildings, but improvements are still required for making this technology fully attractive in the future.

The difference between performance evaluated on one single day and over a whole season is also important to point out: single-day performance can be quite significantly overestimated $(+30 \%)$ compared to seasonal averages, even when the selected single day is far from being the brightest day of the season. Part of that difference can be theoretically

Pons M., Anies G., Boudehenn F., Bourdoukan P., Castaing-Lasvignottes J., Evola G., Le Denn A., Le Pierrès N., Marc O., Mazet N., Stitou D., and Lucas F., Performance comparison of six solarpowered air-conditioners operated in five places, Energy, 46, pp.471-483 (DOI: 10.1016/j.energy.2012.08.002), 2012. 
interpreted as a non-linear effect related to the thermal inertia of the solar field. It thus can be also concluded that performance data based on single day operation are poorly reliable. This is why there is thus a great need for long-term experimentations like those described herein, complemented with refined analysis of all the energy and mass fluxes.

\section{Acknowledgements}

This comparative study was done in the framework of the ORASOL project, financed by the Agence Nationale de la Recherche (ANR) via its program PREBAT (project\# ANR-06PBAT-009-05) and coordinated by Dr. F. Lucas (PIMENT, Univ. La Réunion, France).

The SOLERA unit in Le Bourget-du-Lac was also financed in the framework of the SOLERA project, co-funded by the European Commission within the FP6 (contract number 038627) and coordinated by Dr. T. Núñez (Fraunhofer ISE, Freiburg, Germany), the memory of whom we all are faithful. The Aquisol project in Pau was also financed by the region Aquitaine. The experiment Desic in La Rochelle was supported by both ADEME (the French agency for environment and energy management) and regional council of Poitou-Charentes. The RAFSOL project in Saint Pierre was financed by the Orasol project and also by both ADEME and regional council of La Reunion.

\section{References}

[1] Nomenclature. Journal of Heat Transfer. 1999;121(4):770-3.

[2] Oke TR, Johnson GT, Steyn DG, Watson ID. Simulation of surface urban heat islands under 'ideal' conditions at night. 2. Diagnosis of causation. Boundary Layer Meteorology. 1991;56(4):339-58.

[3] Santamouris M, Papanikolaou N, Livada I, Koronakis I, Georgakis C, Argiriou A, et al. On the impact of urban climate on the energy consumption of buildings. Solar Energy. 2001;70(3):201-16.

[4] Grossman G. Solar-powered systems for cooling, dehumidification and air-conditioning. Solar Energy. 2002; 72(1):53-62.

[5] Ohkura M, Kodama A. Solar assisted adsorptive desiccant cooling system: estimation of the performance and scale of the desiccant cooling system considering indoor latent heat load. Transactions of the Japan Society of Refrigerating and Air Conditioning Engineers. 2006;23(1):33-44.

[6] Henning HM. Solar assisted air conditioning of buildings - an overview. Applied Thermal Engineering. 2007;27(10):1734-49.

[7] Gommed K, Grossman G. Experimental investigation of a liquid desiccant system for solar cooling and dehumidification. Solar Energy. 2007;81(1):131-8.

[8] Alizadeh S. Performance of a solar liquid desiccant air conditioner - An experimental and theoretical approach. Solar Energy. 2008;82(6):563-72.

Pons M., Anies G., Boudehenn F., Bourdoukan P., Castaing-Lasvignottes J., Evola G., Le Denn A., Le Pierrès N., Marc O., Mazet N., Stitou D., and Lucas F., Performance comparison of six solarpowered air-conditioners operated in five places, Energy, 46, pp.471-483 (DOI: 10.1016/j.energy.2012.08.002), 2012. 
[9] Pongtornkulpanich A, Thepa S, Amornkitbamrung M, Butcher C. Experience with fully operational solar-driven 10-ton $\mathrm{LiBr} / \mathrm{H} 2 \mathrm{O}$ single-effect absorption cooling system in Thailand. Renewable Energy. 2008;33(5):943-9.

[10] Syed A, Izquierdo M, Rodriguez P, Maidment G, Missenden J, Lecuona A, et al. A novel experimental investigation of a solar cooling system in Madrid. International Journal of Refrigeration Revue Internationale du Froid. 2005;28(6):859-71.

[11] Rodriguez-Hidalgo MC, Rodriguez-Aumente P, Izquierdo-Millan M, Lecuona-Neumann A, Salgado Mangual R. Energy and carbon emission savings in Spanish housing airconditioning using solar driven absorption system. Applied Thermal Engineering. 2008;28(14-15):1734-44.

[12] Abdulateef JM, Sopian K, Alghoul MA, Sulaiman MY. Review on solar-driven ejector refrigeration technologies. Renewable \& Sustainable Energy Reviews. 2009;13(6-7):1338-49.

[13] Chang WS, Wang CC, Shieh CC. Design and performance of a solar-powered heating and cooling system using silica gel/water adsorption chiller. Applied Thermal Engineering. 2009;29(10):2100-5.

[14] Zhai XQ, Wang RZ, Dai YJ, Wu JY, Xu YX, Ma Q. Solar integrated energy system for a green building. Energy and Buildings. 2007;39(8):985-93.

[15] Zhai XQ, Wang RZ. A review for absorbtion and adsorbtion solar cooling systems in China. Renewable \& Sustainable Energy Reviews. 2009;13(6-7):1523-31.

[16] Marc O, Praene JP, Bastide A, Lucas F. Modeling and experimental validation of the solar loop for absorption solar cooling system using double-glazed collectors. Applied Thermal Engineering. 2011;31(2-3):268-77.

[17] Lucas F, Boudehenn F, Amblard S, Castaing-Lasvignottes J, Pons M, Le Pierrès N, et al. ORASOL: A French research program for solar cooling process optimization. In: Collares Pereira M, editor. EUROSUN-2008 1st Int Conf on Solar Heating, Cooling \& Buildings. Lisbon, Portugal: SPES; 2008. p. Article\#351.

[18] Lucas F. ORASOL Web Site. 2007. http://lpbs.univ-reunion.fr/orasol/.

[19] Fong KF, Chow TT, Lee CK, Lin Z, Chan LS. Comparative study of different solar cooling systems for buildings in subtropical city. Solar Energy. 2010;84(2):227-44.

[20] Fong KF, Lee CK, Chow CK, Yuen SY. Simulation-optimization of solar-thermal refrigeration systems for office use in subtropical Hong Kong. Energy. 2011;36(11):6298307.

[21] Ge TS, Ziegler F, Wang RZ, Wang H. Performance comparison between a solar driven rotary desiccant cooling system and conventional vapor compression system (performance study of desiccant cooling). Applied Thermal Engineering. 2010;30(6-7):724-31.

[22] Onan C, Ozkan DB, Erdem S. Exergy analysis of a solar assisted absorption cooling system on an hourly basis in villa applications. Energy. 2010;35(12):5277-85.

[23] Pons M, Grenier P. Experimental data on a solar-powered ice maker using activated carbon and methanol adsorption pair. Transactions of the ASME Journal of Solar Energy Engineering. 1987;109(4):303-10.

Pons M., Anies G., Boudehenn F., Bourdoukan P., Castaing-Lasvignottes J., Evola G., Le Denn A., Le Pierrès N., Marc O., Mazet N., Stitou D., and Lucas F., Performance comparison of six solarpowered air-conditioners operated in five places, Energy, 46, pp.471-483 (DOI: 10.1016/j.energy.2012.08.002), 2012. 
[24] Le Pierres N, Mazet N, Stitou D. Experimental results of a solar powered cooling system at low temperature. International Journal of Refrigeration-Revue Internationale Du Froid. 2007;30(6):1050-8.

[25] Zhai XQ, Wang RZ. Experimental Investigation on a Closed-Cycle Solar Adsorption Cooling System. Conference Experimental Investigation on a Closed-Cycle Solar Adsorption Cooling System, 2009, Zhang XS, Qian H, et al. editors., 2009, p. 1756-62.

[26] Herold KE, Radermacher R, Klein SA. Absorption chillers and heat pumps. Bocca Raton, Florida: CRC Press, 1996.

[27] Chèze D, Boudéhenn F, Papillon P, Mugnier D, Núñez T. Solera demonstrator of small scale solar heating and cooling system in INES office building. ISES Solar World Congress 2011. Kassel, Germany: ISES; 2011.

[28] Marc O, Lucas F, Sinama F, Monceyron E. Experimental investigation of a solar cooling absorption system operating without any backup system under tropical climate. Energy and Buildings. 2010;42(6):774-82.

[29] Praene JP, Marc O, Lucas F, Miranville F. Simulation and experimental investigation of solar absorption cooling system in Reunion Island. Applied Energy. 2011;88(3):831-9.

[30] Kodama A, Goto M, Hirose T, Kuma T. Performance evaluation for a thermal swing honeycomb rotor adsorber using a humidity chart. Journal of Chemical Engineering of Japan. $1995 ; 28: 19-24$.

[31] Bourdoukan P, Wurtz E, Joubert P, Sperandio M. Potential of solar heat pipe vacuum collectors in the desiccant cooling process: Modelling and experimental results. Solar Energy. 2008;82(12):1209-19.

[32] Bourdoukan P, Wurtz E, Joubert P. Experimental investigation of a solar desiccant cooling installation. Solar Energy. 2009;83(11):2059-73.

[33] Spinner B. Ammonia-based thermochemical transformers. Heat Recovery Systems \& CHP. 1993;13(4):301-7.

[34] Stitou D, Mazet N, Mauran S. Experimental investigation of a solid/gas thermochemical storage process for solar air-conditioning. Energy. 2012;41(1):261-70.

[35] Pons M, Meunier F, Cacciola G, Critoph RE, Groll M, Puigjaner L, et al. Thermodynamic based comparison of sorption systems for cooling and heat pumping. International Journal of Refrigeration. 1999;22(1):5-17.

[36] Aprea C, Mastrullo R, Renno C, Vanoli GP. An evaluation of R22 substitutes performances regulating continuously the compressor refrigeration capacity. Applied Thermal Engineering. 2004;24(1):127-39.

[37] Izquierdo MIM, Moreno-Rodriguez A, Gonzalez-Gil A, Garcia-Hernando N. Air conditioning in the region of Madrid, Spain: An approach to electricity consumption, economics and $\mathrm{CO}(2)$ emissions. Energy. 2011;36(3):1630-9.

Pons M., Anies G., Boudehenn F., Bourdoukan P., Castaing-Lasvignottes J., Evola G., Le Denn A., Le Pierrès N., Marc O., Mazet N., Stitou D., and Lucas F., Performance comparison of six solarpowered air-conditioners operated in five places, Energy, 46, pp.471-483 (DOI: 10.1016/j.energy.2012.08.002), 2012. 


\section{Tables}

Table 1: Main technical characteristics of the units

\begin{tabular}{|c|c|c|c|c|c|}
\hline $\begin{array}{c}\text { NAME } \\
\text { (INSTITUTION) }\end{array}$ & $\begin{array}{c}\text { Collectors: } \\
\text { Area - type } \\
\text { (manufacturer) }\end{array}$ & $\begin{array}{c}\text { Hot } \\
\text { storage }\end{array}$ & $\begin{array}{l}\text { Chiller type } \\
\text { cooling power } \\
\text { (manufacturer) }\end{array}$ & $\begin{array}{c}\text { Heat } \\
\text { rejection to } \\
\text { environment }\end{array}$ & $\begin{array}{l}\text { Cold } \\
\text { storage }\end{array}$ \\
\hline $\begin{array}{l}\text { SOLACLIM } \\
\text { (TECSOL, } \\
\text { PROMES) }\end{array}$ & $\begin{array}{c}25 \mathrm{~m}^{2} \\
\text { double glazing } \\
\text { (Schüco) }\end{array}$ & $\begin{array}{l}3001 . \\
\text { water }\end{array}$ & $\begin{array}{c}\text { Silicagel }+\mathrm{H}_{2} \mathrm{O} \\
7.5 \mathrm{~kW} \\
(\text { Sortech) }\end{array}$ & $\begin{array}{c}\text { Drycooler } \\
\text { (aided by } \\
\text { spray) }\end{array}$ & $\begin{array}{l}3001 . \\
\text { water }\end{array}$ \\
\hline $\begin{array}{c}\text { SOLERA } \\
\text { (CEA INES, } \\
\text { LOCIE) }\end{array}$ & $\begin{array}{c}30 \mathrm{~m}^{2} \\
- \\
\text { (Clipsol) }\end{array}$ & $\begin{array}{l}4001 . \\
\text { water }\end{array}$ & $\begin{array}{c}\mathrm{LiBr}+\mathrm{H}_{2} \mathrm{O} \\
4.5 \mathrm{~kW} \\
\text { (Rotartica) }\end{array}$ & $\begin{array}{l}\text { Water to } \\
\text { ground HX }\end{array}$ & $\begin{array}{l}3001 . \\
\text { water }\end{array}$ \\
\hline $\begin{array}{l}\text { RAFSOL } \\
\text { (PIMENT) }\end{array}$ & $\begin{array}{c}90 \mathrm{~m}^{2} \\
\text { double glazing } \\
\text { (Schüco) }\end{array}$ & $\begin{array}{l}15001 . \\
\text { water }\end{array}$ & $\begin{array}{c}\mathrm{LiBr}+\mathrm{H}_{2} \mathrm{O} \\
30 \mathrm{~kW} \\
(E A W)\end{array}$ & $\begin{array}{l}\text { Wet cooling } \\
\text { tower }\end{array}$ & $\begin{array}{l}10001 . \\
\text { water }\end{array}$ \\
\hline $\begin{array}{c}\text { AQUISOL } \\
\text { (LATEP) }\end{array}$ & $\begin{array}{c}16.6 \mathrm{~m}^{2} \\
\text { vacuum } \\
\text { (see text) }\end{array}$ & $\begin{array}{l}2601 . \\
\text { water }\end{array}$ & $\begin{array}{c}\mathrm{LiBr}+\mathrm{H}_{2} \mathrm{O} \\
4.5 \mathrm{~kW} \\
(\text { Rotartica) }\end{array}$ & Dryc & - \\
\hline $\begin{array}{l}\text { DESIC } \\
\text { (LEPTIAB, } \\
\text { INES) }\end{array}$ & $\begin{array}{c}40 \mathrm{~m}^{2} \\
\text { vacuum } \\
\text { (Thermomax) }\end{array}$ & $\begin{array}{c}23001 . \\
\text { water }\end{array}$ & $\begin{array}{c}\text { Silicagel wheel } \\
\text { + humid air, } \\
15 \mathrm{~kW} \\
\text { [see text] }\end{array}$ & - & - \\
\hline $\begin{array}{l}\text { CLIMSOL } \\
\text { (PROMES) }\end{array}$ & $\begin{array}{c}21.6 \mathrm{~m}^{2} \\
- \\
\text { (HelioAkmi) }\end{array}$ & $\begin{array}{c}380 \mathrm{~kg} \\
\mathrm{PCM} / \mathrm{ENG} \\
\text { [see text] }\end{array}$ & $\begin{array}{c}\mathrm{BaCl}_{2}+\mathrm{NH}_{3} \\
{[\text { see text }]} \\
\text { (promes) }\end{array}$ & $\begin{array}{l}\text { Outdoor HX } \\
+ \text { water to } \\
\text { ground HX }\end{array}$ & $\begin{array}{c}400 \mathrm{~kg} \\
\mathrm{PCM} / \mathrm{ENG} \\
{[\text { see text }]}\end{array}$ \\
\hline $\begin{array}{l}\text { UC3M } \\
\text { (CSIC) }\end{array}$ & $\begin{array}{c}50 \mathrm{~m}^{2} \\
- \\
\text { (Viessmann) }\end{array}$ & $\begin{array}{l}20001 . \\
\text { water }\end{array}$ & $\begin{array}{c}\mathrm{LiBr}+\mathrm{H}_{2} \mathrm{O} \\
35 \mathrm{~kW} \\
(\text { Yazaki) }\end{array}$ & $\begin{array}{l}\text { Open wet } \\
\text { cooling- } \\
\text { tower }\end{array}$ & - \\
\hline
\end{tabular}

Table 2: Experimental conditions for the six French units and the Spanish one UC3M, with one line per year of operation $[10,11]$.

\begin{tabular}{|c|c|c|c|c|c|c|c|}
\hline & Solaclim & Solera & Rafsol & Aquisol & Desic & Climsol & UC3M \\
\hline Number of operation days & 110 & 130 & 163 & 12 & 6 & 65 & 20 \\
& & 115 & 164 & & & 153 & 120 \\
& & & 69 & & & & \\
\hline Average daily insolation & 5.7 & 5.4 & 5.4 & 5.4 & 4.3 & 4.9 & 6.9 \\
{$\left[\mathrm{kWh}\right.$ d. $\left.{ }^{-2}\right]$} & & 4.8 & 4.4 & & & 4.7 & 6.5 \\
& & & 5.4 & & & & \\
\hline Ratio of effective operation & 88 & 99 & 88 & - & - & - & - \\
{$[\%]$} & & 97 & 87 & & & & \\
\hline
\end{tabular}

Pons M., Anies G., Boudehenn F., Bourdoukan P., Castaing-Lasvignottes J., Evola G., Le Denn A., Le Pierrès N., Marc O., Mazet N., Stitou D., and Lucas F., Performance comparison of six solarpowered air-conditioners operated in five places, Energy, 46, pp.471-483 (DOI: 10.1016/j.energy.2012.08.002), 2012. 
Table 3: Performance comparison based on solar COP $\overline{C O P_{\text {sol }}}$, electricity consumption $\overline{\omega_{e l}}$, water consumption $\overline{c_{w}}$ in $\left[1 . \mathrm{kWh}_{\text {cold }}{ }^{-1}\right]$, collector efficiency, and chiller-COP. Data are reported for whole seasons with one line per year of operation and for one single day with given insolation. The values from University Carlos III Madrid are given as UC3M [10,11].

\begin{tabular}{|c|c|c|c|c|c|c|c|}
\hline & Solaclim & Solera & Rafsol & Aquisol & Desic & Climsol & UC3M \\
\hline$\overline{\mathrm{COP}}$ & 0.09 & 0.12 & 0.20 & 0.19 & 0.13 & 0.09 & 0.09 \\
& & 0.09 & 0.13 & & & 0.08 & 0.07 \\
\hline$\overline{\omega_{\text {el }}}$ & 0.23 & 0.24 & 0.32 & $(0.7)$ & 0.28 & 0.17 & - \\
& & 0.29 & 0.37 & & & 0.16 & \\
\hline$\overline{c_{w}}$ & 0.8 & 0 & 8.3 & 0 & 4.4 & 0 & - \\
& & & 8.1 & & & & \\
\hline$\overline{\eta_{s f}}$ & 0.29 & 0.18 & 0.37 & 0.32 & 0.22 & 0.43 & 0.25 \\
& & 0.14 & 0.24 & & & 0.33 & 0.22 \\
\hline$\overline{C O P_{c h}}$ & 0.30 & 0.69 & 0.56 & 0.61 & 0.62 & 0.20 & 0.34 \\
& & 0.67 & 0.53 & & & 0.26 & 0.33 \\
\hline $\mathrm{COP}_{\text {sol, }, 1 d}$ & 0.11 & 0.15 & 0.23 & 0.24 & 0.22 & 0.12 & 0.11 \\
\hline$\eta_{s f, 1 d}$ & 0.33 & 0.22 & 0.39 & 0.39 & - & 0.40 & 0.26 \\
\hline $\mathrm{COP}_{\text {ch,1d }}$ & 0.34 & 0.69 & 0.60 & 0.61 & - & 0.32 & 0.42 \\
\hline
\end{tabular}

Table 4: Results of the first-order model of the solar field when applied to data of the Solera and Rafsol units (resp. Le Bourget du Lac and La Réunion): Values of the two adjusted quantities, and modeled ratios $q_{h} / q_{\text {sol }}$, either for the single day (index $1 \mathrm{~d}$ ) or averaged over the whole season (with bar over).

\begin{tabular}{|c|c|c|c|c|}
\hline & $\overline{q_{s t}}\left[\mathrm{kWh} \cdot \mathrm{m}^{-2}\right]$ & $\overline{\dot{q}_{d}}\left[\mathrm{~kW} \cdot \mathrm{m}^{-2}\right]$ & $q_{h, 1 d}^{*} / q_{\text {sol, } 1 d}$ & $\overline{q_{h}^{*}} / \overline{q_{\text {sol }}}$ \\
\hline Solera & 1.65 & 0.317 & 0.37 & 0.34 \\
\hline Rafsol & 1.31 & 0.339 & 0.43 & 0.39 \\
\hline
\end{tabular}

Pons M., Anies G., Boudehenn F., Bourdoukan P., Castaing-Lasvignottes J., Evola G., Le Denn A., Le Pierrès N., Marc O., Mazet N., Stitou D., and Lucas F., Performance comparison of six solarpowered air-conditioners operated in five places, Energy, 46, pp.471-483 (DOI: 10.1016/j.energy.2012.08.002), 2012. 


\section{Figures}

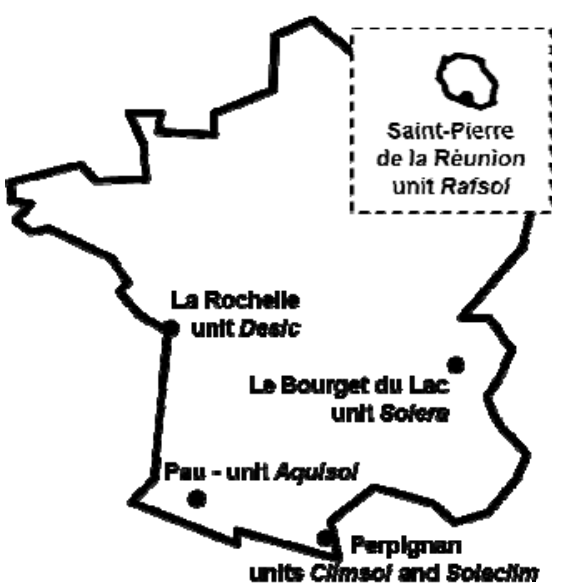

Figure 1: Locations and names of the six solar air-conditioners under test. Five are in metropolitan France, the sixth one is on the tropical island La Réunion

(shown in the dashed frame).

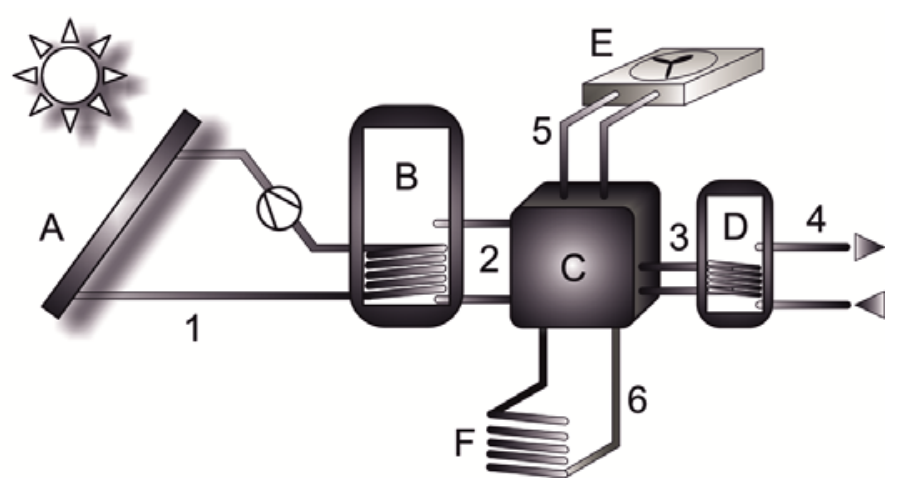

Figure 2: General principle of a solar-powered air-conditioner. A: solar collectors; B: hot storage; C: chiller; D: cold storage; E: cooling tower for heat rejection; F: ground heatexchanger. The six heat-transfer loops are 1: primary loop from solar collectors to hot storage;

2: secondary loop from hot storage to chiller; 3: cold loop from chiller to cold storage: 4: distribution loop from cold storage to cold distribution (e.g. fan-coils); 5: rejection loop from chiller to cooling tower; 6: rejection loop from chiller to ground heat-exchanger.

Pons M., Anies G., Boudehenn F., Bourdoukan P., Castaing-Lasvignottes J., Evola G., Le Denn A., Le Pierrès N., Marc O., Mazet N., Stitou D., and Lucas F., Performance comparison of six solarpowered air-conditioners operated in five places, Energy, 46, pp.471-483 (DOI: 10.1016/j.energy.2012.08.002), 2012. 


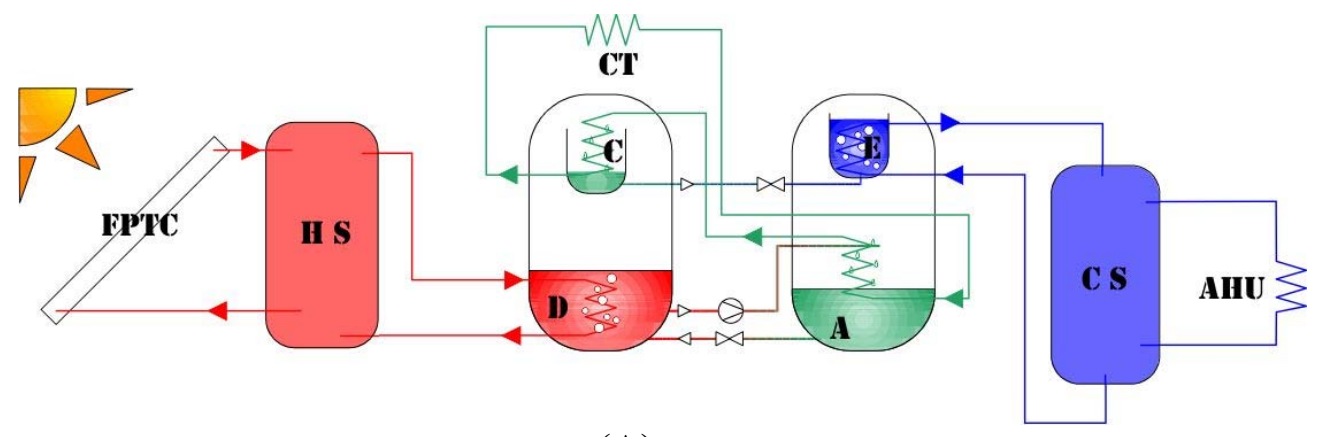

(A)

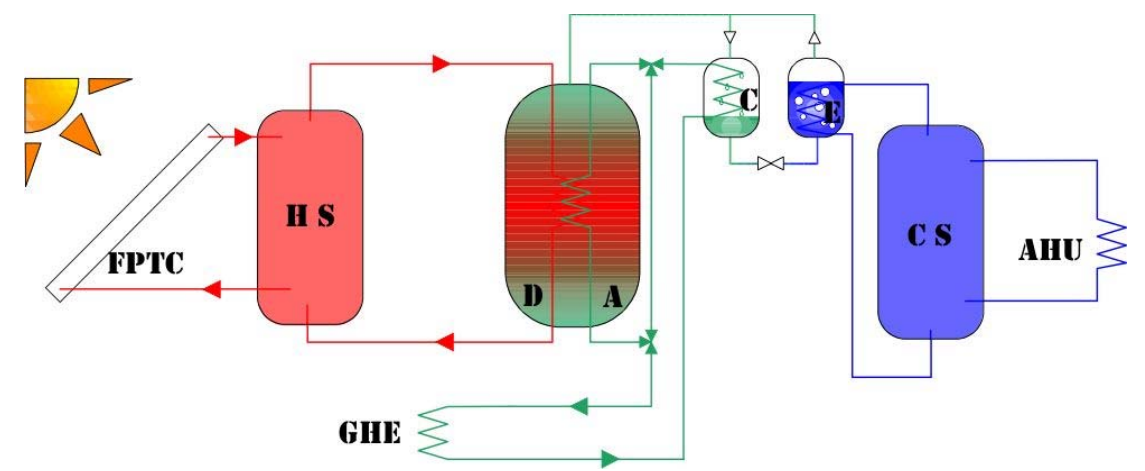

(B)

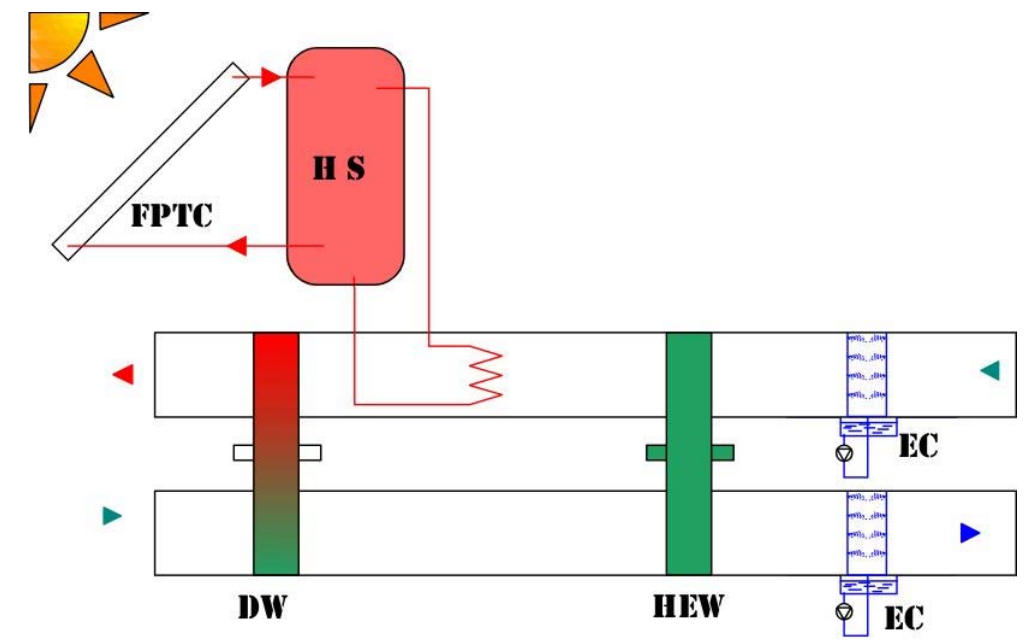

(C)

Figure 3: Respective principles of liquid sorption chillers (A), solid sorption chillers (B), and desiccant-wheel chillers (C). FPTC: flat-plate thermal collector; HS: hot storage; CS: cold storage; D: desorber (generator); C: condenser; E: evaporator, A: absorber; CT: cooling tower; AHU: cold distribution circuit; GHE: ground heat exchanger; EC: evaporative cooler; DW: desiccant wheel; HEW: heat-exchange wheel. Heat can be rejected via a cooling tower, via a ground heat-exchanger, or via both like for the Climsol unit. For solid sorption, there can be one absorber/desorber for 24-hour long cycles (unit Climsol), or two for short cycles (unit Solaclim).

Pons M., Anies G., Boudehenn F., Bourdoukan P., Castaing-Lasvignottes J., Evola G., Le Denn A., Le Pierrès N., Marc O., Mazet N., Stitou D., and Lucas F., Performance comparison of six solarpowered air-conditioners operated in five places, Energy, 46, pp.471-483 (DOI: 10.1016/j.energy.2012.08.002), 2012. 


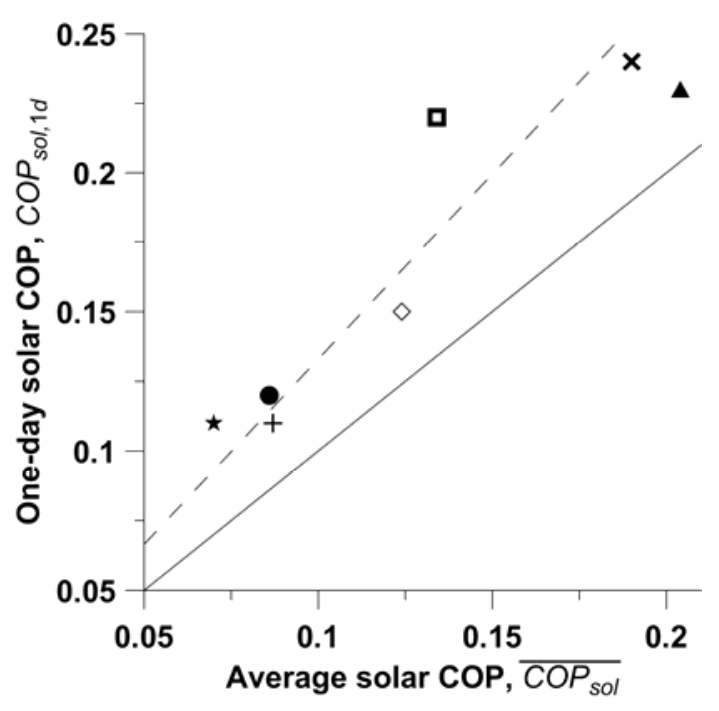

Figure 4: Comparison of seasonal average and one-day value of solar COP for the six units described herein and the UC3M unit reported in [10] (symbol $\star$ ). The solid line shows equality and the dashed line the ratio 1.33 .

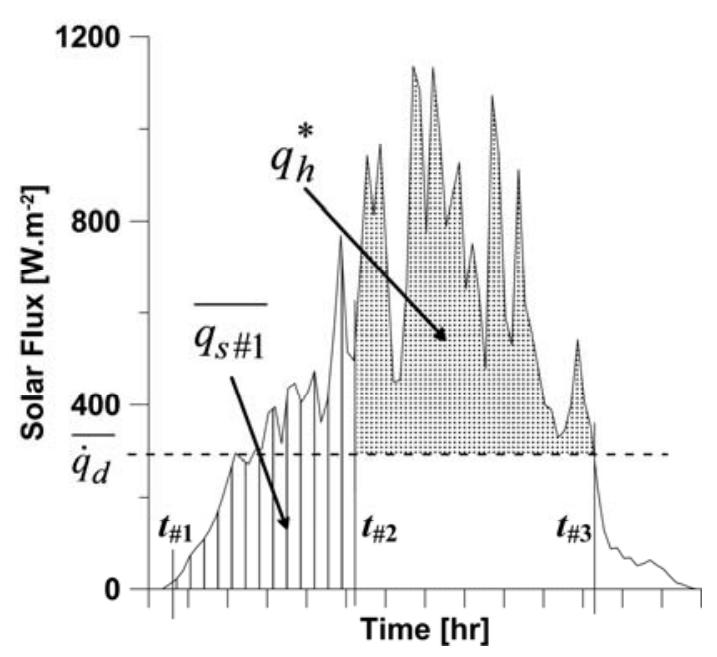

Figure 5: Graphical representation of the operation of a solar-powered chiller. Between $t_{\# 1}$ and $t_{\# 2}$, solar heat is stored into the solar loop for preparing operation (hatched surface); the chiller is switched-off. Between $t_{\# 2}$ and $t \# 3$, only the part of insolation lying over the dissipation rate is transferred to the chiller (grey surface).

Pons M., Anies G., Boudehenn F., Bourdoukan P., Castaing-Lasvignottes J., Evola G., Le Denn A., Le Pierrès N., Marc O., Mazet N., Stitou D., and Lucas F., Performance comparison of six solarpowered air-conditioners operated in five places, Energy, 46, pp.471-483 (DOI: 10.1016/j.energy.2012.08.002), 2012. 